\title{
The spectro-contextual encoding and retrieval theory of episodic memory
}

\author{
Andrew J. Watrous ${ }^{1,2}$ * and Arne D. Ekstrom ${ }^{1,3,4}$ * \\ ${ }^{1}$ Center for Neuroscience, University of California, Davis, CA, USA \\ 2 University of Bonn, Bonn, Germany \\ ${ }^{3}$ Neuroscience Graduate Group, University of California, Davis, CA, USA \\ ${ }^{4}$ Department of Psychology, University of California, Davis, CA, USA
}

\section{Edited by:}

Emrah Duzel, University College London, UK

\section{Reviewed by:}

Christian Doeller, Radboud University Nijmegen, Netherlands

Joshua Jacobs, Drexel University, USA

\section{*Correspondence:}

Arne D. Ekstrom, Center for

Neuroscience, University of California 1544 Newton Court, Davis, CA 95618, USA

e-mail: adekstrom@ucdavis.edu; Andrew J. Watrous, University of Bonn, Sigmund Freud Strasse 25, 53127 Bonn, Germany

e-mail: andrew.j.watrous@gmail.com
The spectral fingerprint hypothesis, which posits that different frequencies of oscillations underlie different cognitive operations, provides one account for how interactions between brain regions support perceptual and attentive processes (Siegel etal., 2012). Here, we explore and extend this idea to the domain of human episodic memory encoding and retrieval. Incorporating findings from the synaptic to cognitive levels of organization, we argue that spectrally precise cross-frequency coupling and phase-synchronization promote the formation of hippocampal-neocortical cell assemblies that form the basis for episodic memory. We suggest that both cell assembly firing patterns as well as the global pattern of brain oscillatory activity within hippocampal-neocortical networks represents the contents of a particular memory. Drawing upon the ideas of context reinstatement and multiple trace theory, we argue that memory retrieval is driven by internal and/or external factors which recreate these frequency-specific oscillatory patterns which occur during episodic encoding. These ideas are synthesized into a novel model of episodic memory (the spectrocontextual encoding and retrieval theory, or "SCERT") that provides several testable predictions for future research.

Keywords: hippocampus, oscillations, cell assembly, neocortex, phase-synchronization, cross-frequency coupling, context reinstatement, episodic memory

\section{INTRODUCTION: EPISODIC MEMORY AND CONTEXT REINSTATEMENT}

Human episodic memory, the storage, and retrieval of experienced events, is a hallmark of our daily experience. While several factors influence the accuracy of memory retrieval, including the availability of relevant cues, one particularly well-studied factor is similarities between encoding and retrieval. Specifically, memory retrieval is facilitated when it occurs in the original encoding environment (Godden and Baddeley, 1975), an effect called encoding specificity (Tulving and Thomson, 1973). Thus, overlap in sensory and other contextual features between encoding and retrieval is an important determinant of subsequent successful memory retrieval. Yet exactly how this overlap is instantiated within brain neural networks remains unclear.

The hippocampus is a brain region critical to episodic memory (Scoville and Milner, 1957; Vargha-Khadem et al., 1997; Yonelinas et al., 2002) and is thought to underlie this process by binding representations of stimuli with the unique spatiotemporal context underlying an event (Diana et al., 2007; Mitchell and Johnson, 2009; Staresina and Davachi, 2009; Ekstrom et al., 2011). This process is widely assumed to involve interactions between hippocampus and neocortical areas responsible for representing sensory information associated with the original event. An important factor underlying encoding specificity is the reinstatement of similar neural activity to that which occurred during encoding, known as context reinstatement (Marr, 1971; McClelland et al., 1995; Norman and O'Reilly, 2003; Teyler and Rudy,
2007). Thus, we use the term "context" here to refer to both the external environmental factors and internal dynamics which drive neural spiking and oscillatory activity into a specific brain state (Manning et al., 2011). Context reinstatement effects have been well-documented in functional MRI studies (Johnson et al., 2009; Gordon et al., 2013). Moreover, several studies have shown that the same neurons active during encoding are also active during retrieval. For instance, neurons active during encoding of a fear memory were also active during retrieval in rodent hippocampus (Tayler et al., 2012) and memory-related reactivation has also been demonstrated in non-human primates (Hoffman and McNaughton, 2002). In humans, hippocampal neurons that were active during encoding were similarly active during memory retrieval (Cameron et al., 2001; Gelbard-Sagiv et al., 2008). Taken together, these findings suggest that context reinstatement occurs when the same neurons or group of functionally associated neurons (i.e., cell assemblies) that were active during encoding are active again during retrieval. Overall, while the exact overlap of cells that are active during both encoding and retrieval, and how these vary by brain region and even hippocampal subfield, is an area of active research (Tayler et al., 2012), there is little debate that context reinstatement facilitates retrieval and that overlapping neural populations likely underlie this effect.

These core behavioral and neural findings regarding overlap between context and neural patterns of activity between encoding and retrieval, however, leave a fundamental issue unresolved - 
how are specific cell assemblies formed during encoding selectively reactivated during retrieval via neocortical sensory traces? Two mechanisms utilizing the phase of oscillatory brain activity, cross-frequency coupling and phase synchronization (PS), are hypothesized to underlie these processes. First, the phase of low-frequency activity often modulates the amplitude of highfrequency activity, known as cross-frequency coupling (CFC; also known as phase-amplitude coupling; Bragin et al., 1995; Canolty and Knight, 2010). CFC may promote optimal conditions for synaptic plasticity (Canolty and Knight, 2010; Jutras and Buffalo, 2010) and therefore cell assembly formation. CFC has been observed in numerous regions across several tasks and species (Bragin etal., 1995; Chrobak and Buzsáki, 1998; Canolty et al., 2006; Canolty and Knight, 2010) and is likely to be a general motif in neuronal computation. Second, inter-area PS may support the coordination amongst brain areas (Fries, 2005; Knight, 2007; Womelsdorf et al., 2007; Polanía et al., 2012; Siegel et al., 2012; Gu et al., 2013) which is likely necessary for hippocampal-neocortical interactions during memory retrieval (McClelland et al., 1995; Buzsáki, 1996; Nadel and Moscovitch, 1997; Eichenbaum, 2000; Nadel et al., 2000; Norman and O’Reilly, 2003). The available evidence thus suggests that CFC and PS represent strong candidate mechanisms for the coordination of cell assemblies during their initial formation and subsequent reactivation.

Emerging evidence indicates that low-frequency oscillatory activity is also reinstated during memory retrieval (Addante et al., 2011; Manning etal., 2011; Morton etal., 2012; Staudigl and Hanslmayr, 2013). Staudigl and Hanslmayr (2013) manipulated the context under which words were encoded and retrieved and showed that oscillations in the theta band $(4-8 \mathrm{~Hz})$ at retrieval were differentially enhanced when the encoding and retrieval contexts matched. Whereas theta oscillations during encoding did not index subsequent retrieval success (i.e., hits versus misses), increased theta-gamma cross-frequency coupling (source localized to the left MTL) was also observed for hits compared to misses in both context conditions. Further, gamma power was enhanced at different theta phases between the match and mismatch conditions. These findings and others (Manning et al., 2011; Morton et al., 2012) indicate that low-frequency oscillations may support context reinstatement generally and that anatomically distributed theta-gamma CFC reflects item and content specific processing.

Recent findings have extended these observations, showing that frequency-specific patterns of inputs that occur during memory encoding are reinstated during correct retrieval. Wimber et al. (2012) had subjects encode words presented against a 6 or $10 \mathrm{~Hz}$ flickering background. Successful retrieval of words learned under these conditions recapitulated the frequency-specific patterns of oscillatory phase that occurred during encoding. These findings indicate that one aspect of encoding may rely upon the frequency-specific pattern of inputs that occur during initial stimulus processing, in turn leading to frequency-specific patterns of oscillatory activity. According to context reinstatement, retrieval of these encoded patterns would be maximally effective when similar frequency-specific patterns of activity are reinstantiated. Thus, one mechanism that could guide which ensembles are activated during retrieval, facilitating context reinstatement by reactivating the same neurons that were active during encoding, could be frequency-specific patterns of fluctuations in the local field potential. These findings in turn relate to a recent theoretical proposal, the "spectral fingerprint" hypothesis, which we detail below.

\section{SPECTRAL FINGERPRINTS IN MEMORY RETRIEVAL}

Siegel et al. (2012) have recently suggested that frequency-specific oscillatory interactions between the same brain regions may act as a carrier for neural information to mediate different cognitive operations and behaviors. Extending these ideas into the domain of memory retrieval, we have recently provided evidence that human episodic memory retrieval is characterized by frequency-specific interactions between MTL, frontal, and parietal cortices using brain recordings in patients with intractable epilepsy (Watrous et al., 2013a). Patients first performed a spatial navigation task, which provided a novel experience with both spatial and temporal components. During memory retrieval, patients were asked to retrieve either spatial or temporal information, which we have shown to be behaviorally independent in a similar task (Ekstrom et al., 2011; Watrous etal., 2013a). We found robust increases in delta (1-4 Hz) and theta-band (4-8 Hz) phase-synchronization between areas when patients correctly retrieved information from memory. Subsequent findings investigating PS between medial temporal lobe (MTL) and retrosplenial cortex have shown similar results (Foster et al., 2013).

Tallying total functional connectivity for each brain region and adopting a graph theoretic analysis, our results also identified the MTL as a convergence hub for network interactions during memory retrieval. This result is consistent with an influential memory model, Multiple Trace Theory (MTT). MTT argues that the hippocampus is constitutively necessary for memory retrieval by providing the spatial contextual information for a specific memory episode (Nadel and Moscovitch, 1997; Nadel et al., 2000). Further, it argues that the hippocampus binds neocortical feature representations, which are represented by distributed neural ensembles throughout neocortex, into a memory trace. Although MTT has proven highly influential in memory research, its original formulation does not specify the mechanisms by which hippocampal-neocortical binding and interaction occur. Our results, which identified phase-synchronization as a potential coordinating mechanism during retrieval, with the MTL as a hub for these interactions, therefore provide a potential mechanistic basis of MTT. We provide more detail on this idea, and specific predictions generated by incorporating PS into MTT, below.

We also found evidence for spectral fingerprints in memory retrieval. More specifically, retrieving spatial versus temporal information led to frequency-specific changes in low-frequency PS. Spatial retrieval was characterized by delta-band synchronization and temporal retrieval was characterized by theta-band synchronization, raising the possibility of frequency multiplexing in episodic memory. This finding has led us to explore, from a mechanistic perspective, how spectral fingerprints could be implemented in episodic memory encoding and retrieval. Here, we 
extend the notion of spectral fingerprints in episodic memory by arguing that frequency-specific oscillations not only act as a medium for inter-regional interaction but also represent part of the episodic engram itself.

We argue that frequency-specificity is a notable feature across several levels of organization (Figure 1), including synaptic and neuronal resonance (Hutcheon and Yarom, 2000), frequency and phase specific cell assembly activity (Jacobs et al., 2007; Canolty et al., 2010, 2012), and finally frequency-specific

\section{Key elements of SCERT}

\section{Synapses- Synaptic Plasticity \& Resonance}

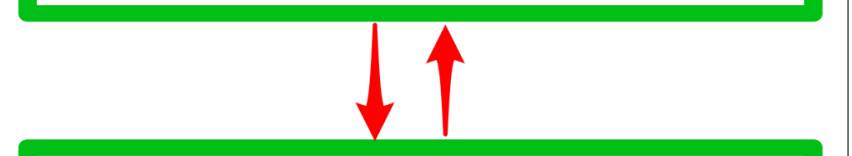

\section{Neurons- Frequency-specific neuronal phase locking}

$$
\downarrow \uparrow
$$

\section{Assemblies- Frequency \& phase specific internal receptive fields}

$$
\downarrow \uparrow
$$

\section{Networks- Phase resetting of frequency} specific oscillations

\section{4}

\section{Brain/Behavior- Context reinstatement via multiple frequency-} specific oscillations

\section{Environment- Partially rhythmic sensory inputs}

FIGURE 1 | Levels of organization in neural systems and the associated findings at each level relevant for SCERT. context reinstatement (Wimber et al., 2012) and memory retrieval (Watrous et al., 2013a). Thus, we suggest that context reinstatement is characterized by interactions at multiple levels: frequency coding at the "macro" level to activate the same ensembles that were active during encoding, CFC to activate the correct neurons at the correct phase of the oscillation, and synapse-frequency dependence to activate the correct synapses of the ensemble and thereby reinstate similar patterns of action potential sequences. While definitive answers are forthcoming, we synthesize these ideas into a new framework, the "SCERT," that provides a number of testable predictions for future research.

\section{PHASE-CODED REPRESENTATIONS OF ITEMS AND FEATURES}

Several studies suggest that the representation of specific items (letters or pictures) or perceptual features results in spatially distributed patterns of high-gamma oscillatory power (Liu et al., 2009; van Gerven et al., 2013) coupled to theta phase (Jacobs and Kahana, 2009). For instance, Jacobs and Kahana (2009) reported that letter-specific gamma activity was phase-locked to theta, arising at the peak of theta and continuing to the theta trough. In another intracranial case study, Jacobs et al. (2012) showed that stimulation at a site in the left temporal lobe elicited memories of the patient's high school experience. Further, visualization of high school information led to category-specific CFC between theta phase and high-gamma amplitude. These studies indicate that phase-coded information, often found in animal studies, is also relevant for stimulus representation and episodic memory in humans.

There is also evidence that spatially distributed patterns of phase form part of the content of a stimulus representation. Recoding from monkey frontal and parietal cortices during a working memory paradigm, Salazar etal. (2012) have shown that phase-synchronized activity between areas varies as a function of the item held in memory. Moreover, the spatial pattern of oscillatory activity within sensory cortices conveys information about categorical stimulus properties (Ohl et al., 2001) and changes following learning (Freeman and Schneider, 1982). Consistent with these observations, it has recently been proposed that oscillatory activity can act as "metadata" to multiplex a population coded signal representing a stimulus [for review on multiplexing in neural systems, see Akam and Kullman (2014) Nature Reviews Neuroscience]. Collectively, these studies support the hypothesis that frequency-specific oscillatory activity likely carries additional information related to item representations during memory.

Gamma activity in turn appears to be related, at least in some cases, to neuronal firing rate (Crone et al., 1998; Manning et al., 2009; Whittingstall and Logothetis, 2009; Miller, 2010) but see also (Bragin et al., 1995; Henrie and Shapley, 2005; Ekstrom et al., 2009). Thus, spatially distributed low-frequency phase coupled gamma activity, as a manifestation of local neuronal firing, could reflect representations of items or features in the environment. This idea is in turn in agreement with the view that spatially distributed co-activating cell assemblies reflect neural information (Hebb, 1949). Together, these findings implicate phase coding of information via local and distant unit phase-locking, 
CFC, and phase-synchronization. The exact frequency at which low-frequency phase coding appears to vary based on a number of intrinsic and extrinsic factors (discussed below). As a consequence, initial encoding of information may yield a "spectral fingerprint" of frequency-specific patterns of oscillatory activity that are then reinstated in a frequency-specific manner during retrieval.

\section{HIPPOCAMPAL EPISODIC ENCODING AND ACTIVE MAINTENANCE}

Decades of work have established that the hippocampus is necessary for episodic memory encoding (Scoville and Milner, 1957; Vargha-Khadem etal., 1997; Yonelinas et al., 2002) and recent evidence has indicated hippocampal involvement in "active" working memory maintenance (Ranganath and D'Esposito, 2001; Ranganath and Blumenfeld, 2005; Axmacher et al., 2008, 2010a,b; Cashdollar et al., 2009; van Vugt et al., 2010). Working memory maintenance, which contributes to episodic encoding (Ranganath and D'Esposito, 2001; Ranganath and Blumenfeld, 2005; Ranganath etal., 2005; Axmacher etal., 2008, 2010a,b; Cashdollar et al., 2009; Khader et al., 2010; van Vugt et al., 2010), is associated with theta-gamma cross-frequency coupling and behavioral performance in humans (Axmacher etal., 2010a). Axmacher etal. (2010a) have shown that the frequency of the phasemodulating signal decreases with increasing memory load. The ratio of theta to gamma frequency, however, remained approximately constant, similar to findings in rodents (Bragin et al., 1995) and consistent with models of theta-gamma interactions underlying memory (Jensen and Lisman, 1998). Also consistent with these models, maintenance is associated with periodic replay of maintained items at theta frequency (Jensen and Lisman, 1998; Fuentemilla etal., 2010). Together, these studies are consistent with the idea, discussed above, that individually maintained elements are manifest as gamma oscillatory activity phase-coded by the theta rhythm (Lisman and Idiart, 1995; Lisman and Jensen, 2013). Thus, phase coding of oscillatory activity during working memory maintenance may also be used to promote episodic encoding in the hippocampus and neocortex.

\section{HIPPOCAMPAL “BINDING" DURING EPISODIC ENCODING}

Memory encoding requires the formation of arbitrary associations amongst different types of information. These include items, such as who or what, and contexts, such as when or where. Memory models suggest that the hippocampus may be important for the associational, or "binding," of these disparate types of information (Diana et al., 2007; Eichenbaum et al., 2007), each of which have been found in the MTL. For instance, single neurons have been found which are selective for different items (Quiroga et al., 2005, 2009; Mormann et al., 2008a, 2011; Gelbard-Sagiv et al., 2008), locations (O'Keefe and Dostrovsky, 1971; Ekstrom et al., 2003; Jacobs et al., 2013), time periods (Macdonald et al., 2011; Kraus et al., 2013), and combinations of these variables (Ekstrom et al., 2003; Macdonald et al., 2011; Kraus et al., 2013). Here, we argue that mechanisms capable of associating the activity of these exemplar classes of neurons, such as CFC and PS, are likely to underlie memory encoding.

\section{OSCILLATORY MECHANISMS FOR CELL-ASSEMBLY FORMATION}

Low-frequency oscillatory activity can dictate the form of synaptic potentiation that is induced, with long term potentiation (LTP) occurring more under conditions of theta activity (Huerta and Lisman, 1993) and when stimulation occurs at the theta peak (Pavlides et al., 1988; Huerta and Lisman, 1993; Huerta and Lisman, 1995). Conversely, synaptic depression is induced at the trough of hippocampal theta (Pavlides et al., 1988; Huerta and Lisman, 1995; Hölscher et al., 1997). Low-frequency phase may also provide a second mechanism for cell assembly formation by promoting spike-timing dependent plasticity (STDP). This form of plasticity relies on coincident spiking between cells with timing in the gamma frequency range (Markram et al., 1997; Caporale and Dan, 2008; Jutras and Buffalo, 2010) and has been indirectly observed in human cortex (Koch et al., 2013). It follows from these studies that mechanisms which coordinate neuronal activity relative to oscillatory phase, such as CFC and PS, influence cell assembly formation (Axmacher et al., 2006; Canolty and Knight, 2010) by regulating synaptic strength and promoting STDP. Together, these studies imply that phase coding, through CFC and phase-synchronization, may be a general mechanism of information processing and memory encoding in the hippocampus (Hasselmo et al., 2002; Harris et al., 2003; Huxter et al., 2003; Lopour et al., 2013).

\section{PHASE-LOCKED NEURONAL ACTIVITY UNDERLIES MEMORY ENCODING}

Several animal studies have found low-frequency phase-locking of single neurons relative to local and distant oscillatory activity relates to visual working memory and/or memory encoding (Jones and Wilson, 2005; Lee et al., 2005; Paz et al., 2008; Siegel et al., 2009; Liebe etal., 2012). Complementary findings have also been observed in human single unit recordings. Rutishauser et al. (2010) have shown that phase-locking of hippocampal neurons to delta and theta $(2-10 \mathrm{~Hz})$ oscillatory activity predicts successful encoding of words into human long-term memory. In accord with the hypothesis that working memory maintenance via CFC may also support long-term memory encoding, hippocampal theta-gamma CFC increases during learning of itemcontext associations in rodents (Tort et al., 2009), suggesting that CFC underlies item-context binding. Similarly, theta-gamma coupling in inferotemporal cortex increases upon learning during a face discrimination task (Kendrick et al., 2011) and thetagamma power comodulation predicts correct memory retrieval (Shirvalkar et al., 2010). Finally, increases in hippocampal EEG phase-locking (Fell etal., 2008) and hippocampal delta, theta, and gamma-band phase-synchronization (Fell et al., 2001, 2003, 2006, 2008; Jutras et al., 2009) accompanies successful encoding in the MTL.

Additional mechanisms exist for the promotion of specific phase relations amongst neuronal ensembles. Phase entrainment (Lakatos etal., 2008) and/or phase-resetting (Axmacher et al., 2006; Jutras and Buffalo, 2010) of ensemble activity may coordinate specific phase relations between assemblies to ensure that hippocampal inputs arrive at the proper theta phase to promote LTP (Axmacher et al., 2006; Fell and Axmacher, 2011). Consistent with the idea that encoding and retrieval occur on different phases of hippocampal theta (Hasselmo et al., 2002; Manns et al., 2007; 
Lever et al., 2010; Douchamps et al., 2013), phase resets occur to different phases of theta during memory encoding and retrieval (Rizzuto et al., 2006). Critically, phase resetting has been observed during working memory, encoding, and retrieval (Givens, 1996; Rizzuto et al., 2003, 2006; McCartney et al., 2004; Mormann et al., 2005). In sum, the evidence supports the notion that multiple mechanisms exist to coordinate neuronal activity relative to oscillatory phase during learning and remembering throughout the brain.

\section{HIPPOCAMPAL-NEOCORTICAL MECHANISMS OF EPISODIC ENCODING}

Declarative memory is thought to rely on a distributed hippocampal-neocortical system (Buzsáki, 1996; Eichenbaum, 2000). Thus, it is important to identify mechanisms of cortical encoding and how this relates to hippocampal activity. Recent findings indicate that the local oscillatory environment causally influences cortical neuronal firing, known as ephaptic coupling (Anastassiou et al., 2011). Anastassiou et al. (2011) performed simultaneous intracellular and extracellular recordings from rodent cortical slices in vitro while concurrently mimicking an extracellular field via stimulation. The authors found that extracellular fields (particularly below $8 \mathrm{~Hz}$ ) can phase entrain single neurons and coordinate spiking activity of groups of neurons in the absence of synaptic activity. These results suggest two important inferences. First, ephaptic coupling may provide a mechanism for the hippocampus to coordinate neocortical activity in the absence of structural connectivity, particularly in light of the fact that the hippocampus does not heavily project directly to neocortical areas (Lavenex and Amaral, 2000), which are nonetheless likely to contribute to episodic memory processes. Second, mechanisms that modulate cortical oscillatory activity, such as CFC and PS, may influence the probability of neuronal firing, potentially forming hippocampal-neocortical cell assemblies.

\section{CROSS-FREQUENCY COUPLING}

Theta-gamma coupling is not unique to the hippocampus (Lisman, 2005; Lisman and Jensen, 2013) and recent studies have found increased cortical CFC (Demiralp et al., 2007; Maris et al., 2011; van der Meij et al., 2012) related to novelty (Tsunada et al., 2011) and memory (Canolty et al., 2006; Friese et al., 2013). For instance, Friese et al. (2013) showed that scalp-recorded posterior gamma amplitude is coupled to frontal theta phase during episodic encoding. Moreover, recordings in monkey PFC during working memory showed sequentially maintained items represented as $\sim 3 \mathrm{~Hz}$ phase-coded spiking and gamma activity (Siegel et al., 2009). These studies illustrate the relevance of neocortical CFC for memory encoding processes.

\section{PHASE COHERENCE}

Phase coherence between areas has been implicated as a mechanism for the hippocampal-neocortical communication thought to underlie learning and memory (Weiss and Rappelsberger, 2000; Weiss etal., 2000; Fell and Axmacher, 2011). Benchenane et al. (2010) assessed rodent learning in a Y-Maze while simultaneously recording from the hippocampus and medial prefrontal cortex
(mPFC) of rodents. They found that hippocampal-mPFC coherence increases at the decision point in the maze, particularly following learning, and that mPFC cell pairs showed correlated activity during periods of high-coherence, forming putative coherence-related cell assemblies (CRCA). They further showed that pyramidal neurons shifted their phase-preference to match that of the CRCA. CRCAs were phase-locked to the trough of hippocampal theta, also the phase at which hippocampal cell assemblies operate under some conditions (Harris et al., 2003; Belluscio et al., 2012). Similarly, human cortical activity is also phase-locked to the theta trough (Canolty et al., 2006; Jacobs and Kahana, 2009) and approximately $10 \%$ of neurons in monkey prefrontal cortex are phase-locked to hippocampal population firing (Siapas et al., 2005). In summary, similar to its role in coordinating and forming intra-hippocampal assemblies, we conclude that PS provides a coordinating mechanism between previously dissociated cortical and hippocampal cell assemblies during learning (Battaglia et al., 2011).

If memory encoding involves frequency-specific phase coding of neuronal activity, it follows that there should be mechanisms at the cellular and synaptic levels which can modify the frequency preference of neurons. In fact, there is strong evidence to suggest that these mechanisms exist, which provide a critical link between "macro" level oscillations and "micro" level changes at the cell and synapse.

\section{CELLULAR MECHANISMS OF PHASE-SYNCHRONIZATION AND NEURONAL RESONANCE}

At the cellular level, synaptic plasticity is central to learning and memory processes and is partially mediated by NMDA and AMPA receptors (Bliss and Lomo, 1973; Madison et al., 1991; Redondo and Morris, 2011). These receptors have also been shown to mediate phase-synchronization within the hippocampus. Gu etal. (2013) reported in vitro evidence that NMDA receptor activation led to delta band phase-synchronization increases between septal and temporal regions of CA3. Similar to previous reports (Sirota etal., 2008; Canolty etal., 2010), synchronization between regions also led to enhanced phase-locking between local units and distal oscillatory phases. These results support the idea that phase-synchronization enhances inter-areal synchronization (Fries, 2005; Womelsdorf et al., 2007) and suggest NMDA receptor mediated PS as a cellular mechanism for intrahippocampal interactions. As argued above, these interactions may promote synaptic plasticity (Fell and Axmacher, 2011) via LTP or STDP and would therefore also lead to cell assembly formation (Benchenane et al., 2010).

\section{SYNAPSES AND NEURONS RESONATE AT SPECIFIC AND MODIFIABLE FREOUENCIES}

Plasticity leads to short-term facilitation or depression of synaptic weights. Although studied primarily as a mechanism of synaptic plasticity, facilitation, and depression also act as a high and low-pass filter on synaptic activity, respectively, allowing individual synapses to selectively respond to a narrow range of frequency inputs (Markram et al., 1998; Izhikevich et al., 2003), referred to as "synaptic resonance" (Tohidi and Nadim, 2009). Thus, while activity-dependent, short-term plasticity has the effect 
of strengthening or weakening specific synapses, it also modifies the frequency-preference of these same synapses (Houweling et al., 2002). Individual hippocampal (Chapman and Lacaille, 1999; Pike et al., 2000; Hu et al., 2002; Peters et al., 2005; Wang et al., 2006) and neocortical (Gutfreund et al., 1995; Ulrich, 2002) neurons also display subthreshold resonance in the theta frequency range. Cellular resonance is based upon the passive and active properties of the cell that act as low and high-pass filters, respectively. Factors that influence the active conductance within a cell will therefore affect the cell's resonant frequency (Hutcheon and Yarom, 2000).

Several channels that contribute to the resonance properties of hippocampal cells, such as NMDA receptors and h-channels mediating the h current (Hutcheon and Yarom, 2000; Wang et al., 2006), are also modified via synaptic plasticity. For instance, inducing LTP in rat CA1 pyramidal neurons led to NMDA receptor-mediated modifications to $\mathrm{h}$ channels, resulting in an increased resonance frequency both at the soma and in dendrites (Narayanan and Johnston, 2007). Conversely, induction of long-term depression using $3 \mathrm{~Hz}$ synaptic stimulation downregulated $\mathrm{I}_{\mathrm{h}}$, significantly lowering the resonance frequency of hippocampal CA1 neurons towards $3 \mathrm{~Hz}$ (Brager and Johnston, 2007). These findings were recently extended in a computational modeling study which showed that the frequency preference of model hippocampal neurons increased monotonically with h-channel conductance (Das and Narayanan, 2014). Thus, the frequency preference of hippocampal synapses and neurons are under bi-directional regulatory control by cellular mechanisms also implicated in synaptic plasticity.

\section{NEURONS THAT RESONATE TOGETHER, OPERATE TOGETHER}

These studies have been taken as evidence that hippocampal neurons act as stimulus dependent matched filters which can adaptively alter their frequency response to match the frequency of their inputs (Narayanan and Johnston, 2007). While additional evidence is needed to verify this interpretation, we speculate that the matched filter properties of hippocampal neurons may have interesting consequences for memory encoding. This property of neurons could allow cell assembly formation based on shared frequency preference. In this scheme, rhythmic inputs (detailed below) at frequency $f_{r}$ selectively drive a subpopulation of neurons who resonate maximally at frequency $f_{r}$. This process would also be expected to increase these neurons' resonance to $f_{r}$ (via LTP and modifications affecting the $\mathrm{I}_{\mathrm{h}}$ current) creating a positive feedback loop between resonance and plasticity to promote frequency-specific cell assemblies via Hebbian plasticity. Extending the notion of Hebbian plasticity, we therefore suggest that neurons that resonate together may also operate together in functional cell assemblies.

Consistent with this idea, computational modeling work indicates that network resonance may even develop in networks of neurons which are not intrinsically resonant (Houweling et al., 2002). Moreover, in comparatively simple circuits of resonant neurons, the frequency-preference of a network of neurons tends towards the resonant frequency of individual neurons in the network (Gutfreund et al., 1995; Houweling et al., 2002; Izhikevich et al., 2003; Tohidi and Nadim, 2009). Although the functional consequences of modifying single-neuron and network level resonance have yet to be fully characterized in vivo, these studies indicate that frequency-specificity also occurs at the synaptic level of organization in neural circuits over short time scales. Future work employing computational modeling will be necessary to determine how resonance and plasticity interact under conditions of memory encoding and retrieval.

\section{NEURONAL RESONANCE MODIFIES NEURONAL FUNCTION AND BEHAVIOR}

These studies also imply that, rather than simply an epiphenomenon, resonance impacts the functional properties of neurons. In the rodent hippocampus, genetic manipulations that reduce the theta resonance of CA1 neurons also lead to impairments in spatial memory (Peters et al., 2005), demonstrating a strong relationship between neuronal resonance properties and behavior. Other evidence comes from studies investigating entorhinal cortex (EC), the main interface between the hippocampus and cortical areas (Lavenex and Amaral, 2000). The resonant theta frequency, mediated by $\mathrm{I}_{h}$ (Giocomo and Hasselmo, 2008; Shay et al., 2012), varies along the dorsal-ventral axis of the EC and may regulate the spacing of grid cells (Giocomo et al., 2007). Because these different areas of EC support different aspects of memory and navigation related behavior (Buzsáki and Moser, 2013; Wilson et al., 2013) modifications to the frequency-preference of single neurons would also be expected to impact neuronal computation and behavior. We have argued thus far that frequency-specific processing of inputs is central to episodic encoding. A critical question, then, regards how frequency variability arises in the first place.

\section{SOURCES OF FREOUENCY VARIABILITY IN NEURAL CIRCUITS}

Brain activity can be broadly classified into that which is driven by external, sensory driven input and that which is driven by internal dynamics (Pastalkova et al., 2008; Buzsáki and Moser, 2013). Many aspects of our sensory world, such as natural sounds and speech (Singh and Theunissen, 2003), are inherently rhythmic. Rhythmic stimuli may entrain low-frequency oscillatory activity (Lakatos et al., 2008; Saleh et al., 2010) and CFC. For arrhythmic sensory inputs, rhythmicity may yet be imposed through "active sensing" via motor actions within the environment (Schroeder et al., 2010). For instance, Jutras, Fries, and Buffalo (Jutras et al., 2013) have shown that monkey saccadic eye movements occur in the theta frequency range and lead to hippocampal theta band phase-resetting during memory encoding. Sensory and motor entrainment may therefore impact oscillatory activities in the hippocampus (Ekstrom and Watrous, 2014), in turn setting the stage for enhanced sensory processing and memory encoding.

Seminal studies have shown that various movement-related behaviors elicit different frequencies of oscillatory activity in the hippocampus (Vanderwolf, 1969; Whishaw and Vanderwolf, 1973; Kramis etal., 1975; reviewed in Buzsáki, 2005). Theta frequency increases with increasing movement speed (McFarland etal., 1975; Watrous etal., 2011) and around the time of movement onset and specific behavior-relevant events (LenckSantini etal., 2008). Theta frequency may be reduced under 
novelty (Jeewajee et al., 2008) but see (Penley et al., 2013) and increasing working-memory load (Axmacher et al., 2010a). Functional and/or anatomical factors are also likely to contribute; gamma amplitude is modulated by theta phase in frontal cortex and alpha phase in parietal-occipital cortex (Voytek et al., 2010). Furthermore, the frequency of gamma oscillations dynamically coordinates neurons throughout the MTL (Colgin et al., 2009) and predicts retrieval based upon spatial or sequence memory (Cabral et al., 2014). The frequency of gamma oscillations in different visual cortical areas varies based on attention (Bosman et al., 2012) and stimulus features but is nonetheless dynamically matched between areas (Roberts et al., 2013). By demonstrating frequency locking between cortical areas over fast timescales, the findings of Roberts et al. (2013) establish the viability of matching frequencyspecific patterns of oscillatory activity between encoding and retrieval.

Broadly speaking, numerous sensorimotor, anatomical, and behavioral factors (and likely more) potentially contribute to variability in oscillatory frequency patterns. The relative contribution of each factor to frequency variability has yet to be fully explored and warrants further investigation. For our purposes, the key point is that frequency-specific memory-related cell assemblies may arise from numerous intrinsic and extrinsic sources contributing to variability in oscillatory brain activity. We argue that the brain may harness this variability in service of episodic memory encoding such that an engram is also manifest in content specific oscillatory brain states.

\section{SYNTHESIS \\ EPISODIC ENCODING}

We have synthesized studies across multiple levels of analysis and species, developing an emerging picture of how the hippocampal-neocortical system encodes and retrieves information. The encoding of a novel experience, such as meeting up with an old friend in a new city, is likely to differentially benefit from hippocampal "binding" of arbitrary associations. The encoding of novel experience, in particular, appears to drive hippocampal activity (Knight, 1996; Ranganath and D’Esposito, 2001), with individual neurons increasing their firing rate to novel stimuli (Rutishauser et al., 2006; Jutras et al., 2009). Environmental novelty alters the phase-preference of rodent CA1 neurons such that they fire closer to the peak of theta (Lever et al., 2010) and successful human memory encoding is associated with $2-10 \mathrm{~Hz}$ spike-field coherence at the theta peak (Rutishauser et al., 2010). Novelty may also decrease theta frequency (Jeewajee et al., 2008) which may provide a longer temporal integration window for spiking to occur at the theta peak.

At the assembly level, hippocampal association of items in context is accompanied by theta-gamma CFC (Tort et al., 2009) to induce LTP. Gamma-band PS amongst hippocampal neurons increases in novel spatial environments (Penley et al., 2013) to promote the formation of functional cell assemblies (Axmacher et al., 2006; Jutras and Buffalo, 2010) during successful encoding (Fell et al., 2001; Axmacher et al., 2006; Jutras et al., 2009; Jutras and Buffalo, 2010). Concurrent PS between the hippocampus and neocortex supports the formation of hippocampal-neocortical cell assemblies (Benchenane et al., 2010). Finally, at the synaptic and cellular level, resonance phenomenon contributes to the formation of frequency-specific cellular assemblies such that neurons that resonate together operate together.

\section{RETRIEVAL OF EPISODIC MEMORIES}

The central claim presented here is that frequency-specific patterns of oscillatory activity that occur during encoding are reinstated during memory retrieval. Accordingly, there is evidence for increased CFC (Düzel et al., 2003, 2005; Mormann et al., 2005) and PS (Anderson et al., 2009; Foster et al., 2013; Watrous et al., 2013a) during memory retrieval. The observations of inter-regional neuronal phase-locking and CFC (Sirota et al., 2008) has recently been extended to include more global patterns of oscillatory coupling amongst multiple brain areas (Canolty et al., 2010, 2012). For instance, Canolty et al. (2010) showed that neurons in frontal cortex fire more robustly to specific patterns of global oscillatory phase (termed the neuron's "internal receptive field," IRF) recorded simultaneously from widespread cortical areas. The authors found that adjacent neurons, which are putatively embedded in nearly identical local fields, can have very different IRFs, suggesting that global oscillatory patterns may influence single neurons more strongly than local patterns under some circumstances. Firing rates of individual neurons were modulated as a function of frequency-specific patterns of global oscillatory phase. The majority of neurons showed frequency preference for activity $<8 \mathrm{~Hz}$, reminiscent of findings demonstrating ephaptic coupling in cortex (Anastassiou et al., 2011). These findings indicate that global, frequency, and phase-specific patterns of oscillatory activity influence single neuron firing which may provide a means for cell assembly activation during memory retrieval.

Several lines of evidence suggest that the hippocampus may orchestrate the selection of specific cell assemblies during retrieval (Nadel and Moscovitch, 1997; Canolty et al., 2010; Battaglia et al., 2011) by promoting frequency-specific oscillatory patterns in neocortical areas. First, the hippocampus is well positioned anatomically in the associational cortical hierarchy (Felleman and Van Essen, 1991; Lavenex and Amaral, 2000). Second, the human hippocampus has been observed to show peak oscillatory activity and to function at several frequencies in the $1-10 \mathrm{~Hz}$ band (Jacobs et al., 2007; Axmacher et al., 2010a; Rutishauser et al., 2010; Lega et al., 2011; Watrous et al., 2013b). Third, local delta (Gu et al., 2013) and theta generators with distinct behavioral correlates have been observed in the hippocampus (Mormann et al., 2008b; Goutagny et al., 2009; Montgomery et al., 2009; Watrous et al., 2011). Human intracranial recordings from the neocortex and studies in neocortical slice preparations also indicate that theta is generated mostly locally (Bao and Wu, 2003; Raghavachari et al., 2006) and may occur with multiple peaks in the theta band (Groppe et al., 2013) which could allow independent coordination of multiple cortical regions. While the exact mechanisms of hippocampal to neocortical PS remain unclear, it may be possible for the MTL, via hippocampal projection interneurons, to enhance low-frequency oscillations in neocortical regions by entraining cortical interneurons, in turn driving local cortical activity via ephaptic coupling (Blatow et al., 2003; Tierney et al., 2004). We therefore suggest that the necessary circuitry is in place for intrinsic 
activity patterns in the hippocampus to drive cortical activity to reinstate cortical oscillatory patterns and select a specific cell assembly.

The demonstration of IRFs and similar findings during motor tasks (Canolty et al., 2010, 2012) provides evidence that single neurons are more active under specific, global oscillatory conditions. This raises the possibility that cortical-hippocampal cell assemblies formed during encoding may be similarly activated or selected during memory retrieval by reinstating the global, frequency-specific oscillatory patterns present during encoding. Consistent with the spectral fingerprint hypothesis, Voytek et al. (2010) showed that high-gamma power is phase-locked to multiple low-frequency rhythms at the same time, a version of frequency multiplexing. These findings suggest that cell assemblies may be selected simultaneously based on their response to specific frequencies and phases (Engel et al., 2001; Canolty et al., 2010; Canolty and Knight, 2010; Voytek et al., 2010; van der Meij et al., 2012; Jirsa and Müller, 2013; Watrous et al., 2013a).

\section{THE SPECTRO-CONTEXTUAL ENCODING AND RETRIEVAL "SCERT" THEORY}

Drawing upon the ideas of context reinstatement, spectral fingerprints and multiplexing, MTT, and internal receptive fields, we propose the following model (Figure 2) of episodic memory:

(1) The rhythmic external world and/or rhythmic sensory sampling (active sensing) impose rhythmicity onto sensory inputs. Phase entrainment and phase resetting serve as mechanisms for rhythmic inputs to arrive during periods of heightened local excitability.
(2) Rhythmic inputs act as a frequency and phase specific spectral context during encoding and selectively drive synapses and neurons with similar resonant properties. Neurons that resonate together will also operate together in functional cell assemblies.

(3) Shared frequency preference amongst neurons, CFC, and PS contribute to the formation of a cellular assembly for a specific engram through Hebbian plasticity and STDP. This encoding process strengthens synaptic connections between neurons in the assembly and also modifies their resonance properties to match that of the assembly.

(4) Reactivation of a cell assembly during retrieval is a hippocampally driven process whereby the hippocampus reinstates, largely based on contextual cues, the internal receptive field for a given cell assembly. This process is frequency multiplexed, allowing for the simultaneous reactivation of different assemblies operating at different preferred frequencies.

Spectro-contextual encoding and retrieval theory makes several predictions for future research which can be tested using both correlative and causal methods. First, providing retrieval cues based on real-time detection of brain states should augment memory performance. For instance, presenting a retrieval cue during a window in which oscillatory phases match those present during item encoding should selectively facilitate memory performance for the item. This prediction should be testable in existing datasets.

Second, SCERT predicts that neuronal ensembles that resonate together also operate together. Although difficult to test at the macroscopic level in humans at present, it is in principle possible to identify several single neurons in humans, identify
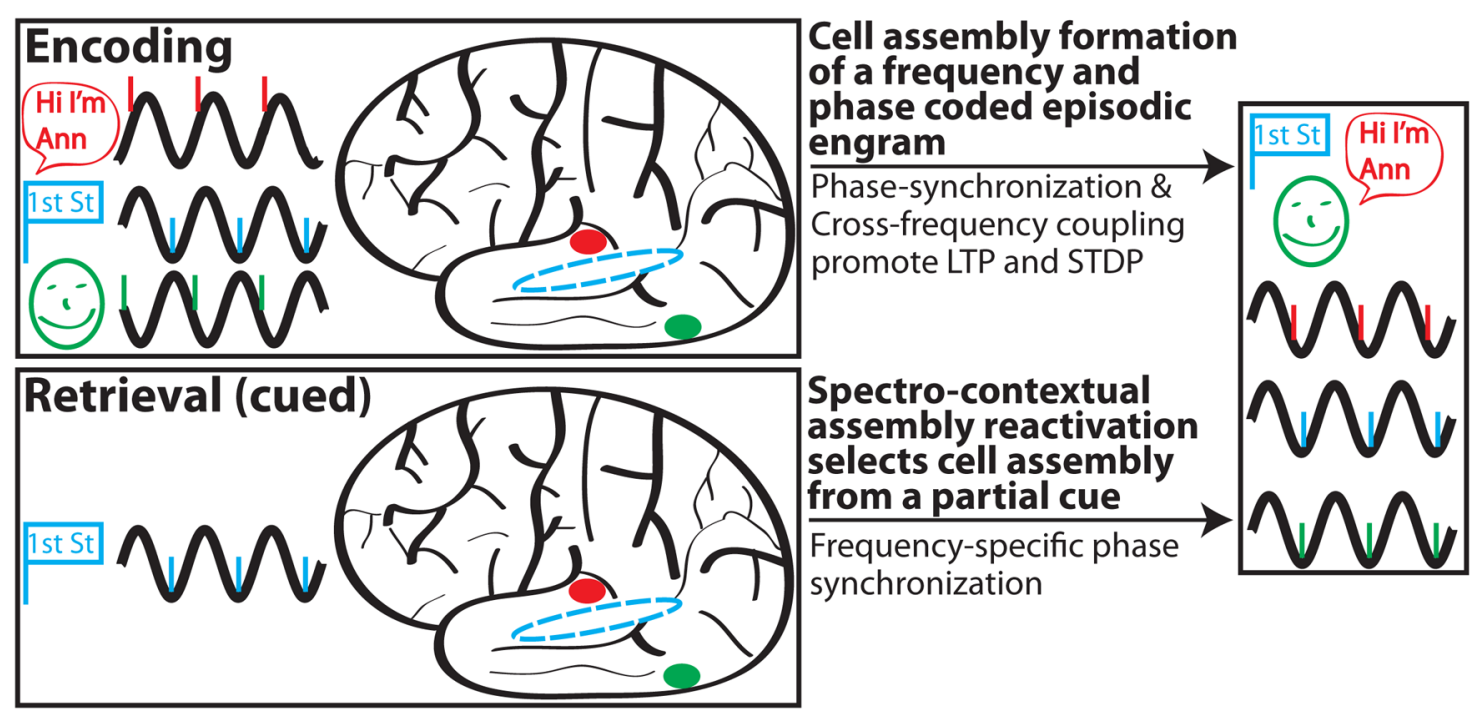

\section{Spectro-contextua assembly reactivation selects cell assembly Frequency-specific phase synchronization}

FIGURE 2 | Schematic depiction of SCERT. In this scenario, a person perceives (via active sensing) and encodes a woman (green) who introduces herself as Ann (red) on the corner of first street (blue). Associated activity in different brain areas is shown for each type of information in a different color; stimulus representations are shown in prototypical brain areas for clarity but may also be more diffusely distributed throughout the brain. Phase-locking of neuronal ensembles for each region is shown for the initial representation and following learning. Episodic encoding is associated with phase synchronization between areas and CFC between assemblies representing different aspects of the experience. During retrieval, a partial cue (encountering first street) initially drives hippocampal activity to reinstate the spectral signature associated with the encoding experience. Note that some aspects of SCERT, including neuronal resonance and frequency multiplexing, are not depicted. 
their frequency and phase preference, and then determine how neurons with similar spectral preferences operate during behavior. Neurons that show multiple frequency and phase-preferences during different behaviors would also provide evidence for frequency multiplexing. Thus, a novel prediction here would be that ensembles representing different components of memory, if stimulated together at the same frequency, could induce novel memories. For example, if one could stimulate representations for "airplane" and "purple stripes" one could create a false memory of a novel purple-striped vehicle even though this had never been experienced before. Although there is evidence to suggest that stimulation can sometimes induce retrieval of remote memories (Jacobs et al., 2012), the veracity of these recalled memories is not typically investigated. Thus, to our knowledge, there is currently no evidence to suggest that DBS can induce recollection of never-before-experienced memories. Based on our theoretical framework, however, we believe that it is reasonable to expect that DBS, perhaps if timed with endogenous hippocampal oscillations using intracranial recordings, could induce veridical memory recall.

There are additional predictions that can be made using causal stimulation methods. It should be possible to manipulate memory performance by experimentally controlling the frequencies under which memories are encoded and retrieved. This could be accomplished either by experimentally controlling the frequency of stimulus presentation or via electrical stimulation methods. For instance, stimulating the hippocampus via deep brain stimulation (DBS) during retrieval at a frequency introduced during encoding should facilitate retrieval by reactivating frequency-specific cortical traces. Thus, if recordings determine that a specific spatial context (say a scene) is encoded via $3-5 \mathrm{~Hz}$ synchronization between the hippocampus and specific ensembles within neocortex, stimulating the hippocampus in concert with these cortical nodes should enhance recollection of the scene and any previously encoded details with this scene. No studies to date have matched stimulation and recordings in the human brain and so this prediction remains novel and untested. Yet, it provides an important link between oscillatory coherence, cortical, and hippocampal cooperation.

Conversely, we predict that inducing a mismatch between encoding and retrieval frequencies will impair memory retrieval by producing a spectral brain state that does not selectively drive the assembly at its preferred IRF. For example, if a scene were encoded via $3-5 \mathrm{~Hz}$ coherence between hippocampus and cortex, stimulating either hippocampus or cortex at this frequency, provided this simulation is out-of-phase with the on-going hippocampal activity, will impair contextual retrieval. During retrieval, a similar effect would result from stimulating at a high frequency that is inconsistent with the encoded frequency. In fact, studies using DBS in hippocampus suggest that stimulating the hippocampus at fast frequencies will disrupt encoding of pictures, which is possible if stimulation occurs out of phase with on-going cortical stimulation or at a different frequency all together from what would typically be induced in cortex (Coleshill et al., 2004). Thus, a novel prediction of SCERT is that stimulating hippocampus out-of-phase phase with cortex, either during encoding or retrieval, will result in impaired memory retrieval.
Finally, episodic encoding should benefit from exogenously induced phase-synchronization between neocortical areas in patients with hippocampal damage or dysfunctional hippocampi. Specifically, inducing neocortical synchronization via methods such as transcranial magnetic stimulation (TMS) or transcranial alternating or direct current stimulation (tACS/tDCS) may facilitate encoding of neocortical memory traces, although these are likely to be more general and semantic in nature. These methods have been used previously to induce human cortical theta PS and causally modulate performance on a simple memory task (Polanía et al., 2012). To the extent that the hippocampus normally provides spatiotemporal contextual information and coordinates neocortical assemblies during encoding, frequencyspecific entrainment of neocortex in these patients may facilitate memory trace formation for some (non-contextual) aspects of an encoding experience. Consistent with our prior prediction, this memory trace may be reactivated in these patients by artificially driving activity to reinstate the IRF of the neocortical memory trace. Thus, SCERT also provides a new prediction for how to partially remediate episodic memory impairments in clinical populations.

\section{OUTSTANDING QUESTIONS}

What are the broader mechanisms responsible for this assembly selection process? We suggest two possibilities to this yet unresolved question. Environmental cues may reactivate a subset of neurons in the cell assembly encoding a specific memory. For instance, seeing a picture of one's high school prom date may activate neuronal populations or specific oscillatory patterns that represent the person. If neurons which resonate together also operate together, this process may ultimately drive activity in the larger, frequency-responsive assembly representing the entire prom experience. This speculative possibility warrants further studies. Second, in the absence of closely associated or rhythmic environmental cues, it may be possible for intrinsic brain dynamics or top-down processes to recreate oscillatory patterns from encoding via local generators of theta activity as discussed above. Given that many cues are not inherently rhythmic, some other source of rhythmicity may be at play, possibly top-down signals from associational cortical areas or active sensing processes (Schroeder et al., 2010; Jutras et al., 2013); these possibilities await further investigation.

Our model of memory encoding and retrieval raises a number of intriguing new questions for future research. First, how does sleep-related reactivation fit into our model? Does memory replay reinforce the spectral patterns which were originally present during encoding? Second, what are the constraining conditions for multiplexing in memory (Schyns et al., 2011; Knight and Eichenbaum, 2013)? Third, what roles do modulations in power and phase play in neuronal computations, and more specifically, what accounts for the observed increases and decreases (Sederberg et al., 2003; Lega et al., 2011; Burke et al., 2013) in low-frequency power during memory tasks? Fourth, what do CFC and PS independently contribute to encoding and retrieval? Fifth, given that LTP and resonance appear to be inter-related phenomenon, what are the conditions in which they share diverging or converging roles in promoting assembly formation and reactivation? 
Finally, unique patterns of oscillatory phase are almost always present in the brain. This activity may be capable of selectively driving assemblies with a specific internal receptive field (Canolty et al., 2010). Why aren't memories spontaneously recalled more often? Future studies will be necessary to address this open question but we offer two speculative possibilities. First, because retrieval cues are needed to drive cell assembly activity to begin with, oscillatory phase dynamics in the absence of cues may not be sufficient to drive specific cell assemblies. Another possibility, consistent with MTT, is that cortical cell assemblies are indeed driven by ongoing oscillatory phase but memory retrieval itself, involving the tying together of these details into a specific episode, requires hippocampal involvement.

In summary, SCERT argues that memory encoding is subserved by synaptic and neuronal resonance, CFC, and PS such that frequency-specific oscillatory activity both forms cell assemblies and contributes to the episodic engram. We provide evidence that a range of factors, including synaptic and neuronal resonance, sensory, motor, and behavioral factors, contribute to frequency-specific oscillatory dynamics. Implementing the ideas of context reinstatement, we argue that retrieval occurs via the hippocampally driven reinstatement of an engram's spectral signature, ultimately driving activity in spatially distributed cell assemblies that code for a specific experience.

\section{ACKNOWLEDGMENTS}

This work was supported by NINDS R01NS076856, the Sloan Foundation, and the Hellman Young Investigator Award. The authors wish to thank the reviewers, along with Liang-Tien Hsieh, Matthias Gruber, Andrew Heusser, Richard Addante, and Hannah Bishop, for their insightful comments on the manuscript.

\section{REFERENCES}

Addante, R. J., Watrous, A. J., Yonelinas, A. P., Ekstrom, A. D., and Ranganath, C. (2011). Prestimulus theta activity predicts correct source memory retrieval. Proc. Natl. Acad. Sci. U.S.A. 108, 10702-10707. doi: 10.1073/pnas.10145 28108

Akam, T., and Kullman, D. M. (2014). Oscillatory multiplexing of population codes for selective communication in the mammalian brain. Nat. Rev. Neurosci. 15, 111-122 doi: 10.1038/nrn3668

Anastassiou, C. A., Markram, H., and Koch, C. (2011). Ephaptic coupling of cortical neurons. Nat. Neurosci. 14, 217-223. doi: 10.1038/nn.2727

Anderson, K. L., Rajagovindan, R., Ghacibeh, G. A., Meador, K. J., and Ding, M. (2009). Theta oscillations mediate interaction between prefrontal cortex and medial temporal lobe in human memory. Cereb. Cortex 1, 15.

Axmacher, N., Henseler, M. M., Jensen, O., Weinreich, I., Elger, C. E., and Fell, J. (2010a). Cross-frequency coupling supports multi-item working memory in the human hippocampus. Proc. Natl. Acad. Sci. U.S.A. 107, 3228-3233. doi: 10.1073/pnas.0911531107

Axmacher, N., Lenz, S., Haupt, S., Elger, C. E., and Fell, J. (2010b). Electrophysiological signature of working and long-term memory interaction in the human hippocampus. Eur. J. Neurosci. 31, 177-188. doi: 10.1111/j.14609568.2009.07041.x

Axmacher, N., Mormann, F., Fernández, G., Elger, C. E., and Fell, J. (2006). Memory formation by neuronal synchronization. Brain Res. Rev. 52, 170-182. doi 10.1016/j.brainresrev.2006.01.007

Axmacher, N., Schmitz, D. P., Wagner, T., Elger, C. E., and Fell, J. (2008). Interactions between medial temporal lobe, prefrontal cortex, and inferior temporal regions during visual working memory: a combined intracranial EEG and functional magnetic resonance imaging study. J. Neurosci. 28, 7304-7312. doi: 10.1523/JNEUROSCI.1778-08.2008
Bao, W., and Wu, J.-Y. (2003). Propagating wave and irregular dynamics: spatiotemporal patterns of cholinergic theta oscillations in neocortex in vitro. J. Neurophysiol. 90, 333-341. doi: 10.1152/jn.00715.2002

Battaglia, F. P., Benchenane, K., Sirota, A., Pennartz, C. M. A., and Wiener, S. I. (2011). The hippocampus: hub of brain network communication for memory. Trends Cogn. Sci. 15, 310-318. doi: 10.1016/j.tics.2011.05.008

Belluscio, M. A., Mizuseki, K., Schmidt, R., Kempter, R., and Buzsáki, G. (2012). Cross-frequency phase-phase coupling between $\theta$ and $\gamma$ oscillations in the hippocampus. J. Neurosci. 32, 423-435. doi: 10.1523/JNEUROSCI.4122-11.2012

Benchenane, K., Peyrache, A., Khamassi, M., Tierney, P. L., Gioanni, Y., Battaglia, F. P., et al. (2010). Coherent theta oscillations and reorganization of spike timing in the hippocampal-prefrontal network upon learning. Neuron 66, 921-936. doi: 10.1016/j.neuron.2010.05.013

Blatow, M., Rozov, A., Katona, I., Hormuzdi, S. G., Meyer, A. H., Whittington, M. A., et al. (2003). A novel network of multipolar bursting interneurons generates theta frequency oscillations in neocortex. Neuron 38, 805-817. doi: 10.1016/S08966273(03)00300-3

Bliss, T. V., and Lomo, T. (1973). Long-lasting potentiation of synaptic transmission in the dentate area of the anaesthetized rabbit following stimulation of the perforant path. J. Physiol. 232, 331-356.

Bosman, C. A., Schoffelen, J. M., Brunet, N., Oostenveld, R., Bastos, A. M., Womelsdorf, T., etal. (2012). Attentional stimulus selection through selective synchronization between monkey visual areas. Neuron 75, 875-888. doi: 10.1016/j.neuron.2012.06.037

Brager, D. H., and Johnston, D. (2007). Plasticity of intrinsic excitability during long-term depression is mediated through mGluR-dependent changes in $\mathrm{I}(\mathrm{h})$ in hippocampal CA1 pyramidal neurons. J. Neurosci. 27, 13926-13937. doi: 10.1523/JNEUROSCI.3520-07.2007

Bragin, A., Jandó, G., Nádasdy, Z., Hetke, J., Wise, K., and Buzsáki, G. (1995). Gamma (40-100 Hz) oscillation in the hippocampus of the behaving rat. J. Neurosci. 15, 47-60.

Burke, J. F., Zaghloul, K. A., Jacobs, J., Williams, R. B., Sperling, M. R., Sharan, A. D., etal. (2013). Synchronous and asynchronous theta and gamma activity during episodic memory formation. J. Neurosci. 33, 292-304. doi: 10.1523/JNEUROSCI.2057-12.2013

Buzsáki, G. (1996). The hippocampo-neocortical dialogue. Cereb. Cortex 6, 81-92. doi: $10.1093 /$ cercor/6.2.81

Buzsáki, G. (2005). Theta rhythm of navigation: link between path integration and landmark navigation, episodic and semantic memory. Hippocampus 15, 827-840. doi: 10.1002/hipo.20113

Buzsáki, G., and Moser, E. I. (2013). Memory, navigation and theta rhythm in the hippocampal-entorhinal system. Nat. Neurosci. 16, 130-138. doi: $10.1038 / \mathrm{nn} .3304$

Cabral, H. O., Vinck, M., Fouquet, C., Pennartz, C. M. A., Rondi-Reig, L., and Battaglia, F. P. (2014). Oscillatory dynamics and place field maps reflect hippocampal ensemble processing of sequence and place memory under NMDA receptor control. Neuron 81, 402-415. doi: 10.1016/j.neuron.2013.11.010

Cameron, K. A., Yashar, S., Wilson, C. L., and Fried, I. (2001). Human hippocampal neurons predict how well word pairs will be remembered. Neuron 30, 289-298. doi: 10.1016/S0896-6273(01)00280-X

Canolty, R. T., and Knight, R. T. (2010). The functional role of cross-frequency coupling. Trends Cogn. Sci. 14, 506-515. doi: 10.1016/j.tics.2010.09.001

Canolty, R. T., Edwards, E., Dalal, S. S., Soltani, M., Nagarajan, S. S., Kirsch, H. E., et al. (2006). High gamma power is phase-locked to theta oscillations in human neocortex. Science 313, 1626-1628. doi: 10.1126/science.1128115

Canolty, R. T., Ganguly, K., and Carmena, J. M. (2012). Task-dependent changes in cross-level coupling between single neurons and oscillatory activity in multiscale networks. PLoS Comput. Biol. 8:e1002809. doi: 10.1371/journal.pcbi. 1002809

Canolty, R. T., Ganguly, K., Kennerley, S. W., Cadieu, C. F., Koepsell, K., Wallis, J. D., et al. (2010). Oscillatory phase coupling coordinates anatomically dispersed functional cell assemblies. Proc. Natl. Acad. Sci. U.S.A. 107, 17356-17361. doi: $10.1073 /$ pnas. 1008306107

Caporale, N., and Dan, Y. (2008). Spike timing-dependent plasticity: a Hebbian learning rule. Annu. Rev. Neurosci. 31, 25-46. doi: 10.1146/annurev.neuro.31.060407.125639

Cashdollar, N., Malecki, U., Rugg-Gunn, F. J., Duncan, J. S., Lavie, N., and Duzel, E. (2009). Hippocampus-dependent and -independent theta-networks 
of active maintenance. Proc. Natl. Acad. Sci. U.S.A. 106, 20493-20498. doi: 10.1073/pnas.0904823106

Chapman, C. A. C., and Lacaille, J. C. J. (1999). Intrinsic theta-frequency membrane potential oscillations in hippocampal CA1 interneurons of stratum lacunosummoleculare. J. Neurophysiol. 81, 1296-1307.

Chrobak, J. J., and Buzsáki, G. (1998). Gamma oscillations in the entorhinal cortex of the freely behaving rat. J. Neurosci. 18, 388-398.

Coleshill, S. G., Binnie, C. D., Morris, R. G., Alarcón, G., van Emde Boas, W., Velis, D. N., et al. (2004). Material-specific recognition memory deficits elicited by unilateral hippocampal electrical stimulation. J. Neurosci. 24, 1612-1616. doi: 10.1523/JNEUROSCI.4352-03.2004

Colgin, L. L., Denninger T., Fyhn, M., Hafting, T., Bonnevie, T., Jensen, O., et al. (2009). Frequency of gamma oscillations routes flow of information in the hippocampus. Nature 462, 353-357. doi: 10.1038/nature08573

Crone, N. E., Miglioretti, D. L., Gordon, B., and Lesser, R. P. (1998). Functional mapping of human sensorimotor cortex with electrocorticographic spectral analysis. II. Event-related synchronization in the gamma band. Brain 121( $\mathrm{Pt} \mathrm{12}$ ), 2301-2315. doi: 10.1093/brain/121.12.2301

Das, A., and Narayanan, R. (2014). Active dendrites regulate spectral selectivity in location-dependent spike initiation dynamics of hippocampal model neurons. J. Neurosci. 34, 1195-1211. doi: 10.1523/JNEUROSCI.3203-13.2014

Demiralp, T., Bayraktaroglu, Z., Lenz, D., Junge, S., Busch, N. A., Maess, B., et al. (2007). Gamma amplitudes are coupled to theta phase in human EEG during visual perception. Int. J. Psychophysiol. 64, 24-30. doi: 10.1016/j.ijpsycho.2006.07.005

Diana, R. A., Yonelinas, A. P., and Ranganath, C. (2007). Imaging recollection and familiarity in the medial temporal lobe: a three-component model. Trends Cogn. Sci. 11, 379-386. doi: 10.1016/j.tics.2007.08.001

Douchamps, V., Jeewajee, A., Blundell, P., Burgess, N., and Lever, C. (2013). Evidence for encoding versus retrieval scheduling in the hippocampus by theta phase and acetylcholine. J. Neurosci. 33, 8689-8704. doi: 10.1523/JNEUROSCI.448312.2013

Düzel, E., Habib, R., Schott, B., Schoenfeld, A., Lobaugh, N., McIntosh, A. R., et al. (2003). A multivariate, spatiotemporal analysis of electromagnetic time-frequency data of recognition memory. Neuroimage 18, 185-197. doi: 10.1016/S1053-8119(02)00031-9

Düzel, E., Neufang, M., and Heinze, H.-J. (2005). The oscillatory dynamics of recognition memory and its relationship to event-related responses. Cereb. Cortex 15, 1992-2002. doi: 10.1093/cercor/bhi074

Eichenbaum, H. (2000). A cortical-hippocampal system for declarative memory. Nat. Rev. Neurosci. 1, 41-50. doi: 10.1038/35036213

Eichenbaum, H., Yonelinas, A. P., and Ranganath, C. (2007). The medial temporal lobe and recognition memory. Annu. Rev. Neurosci. 30, 123-152. doi: 10.1146/annurev.neuro.30.051606.094328

Ekstrom, A. D., Copara, M. S., Isham, E. A., Wang, W.-C., and Yonelinas, A. P. (2011) Dissociable networks involved in spatial and temporal order source retrieval. Neuroimage 56, 1803-1813. doi: 10.1016/j.neuroimage.2011.02.033

Ekstrom, A. D., Kahana, M. J., Caplan, J. B., Fields, T. A., Isham, E. A., Newman, E. L., et al. (2003). Cellular networks underlying human spatial navigation. Nature 425, 184-188. doi: 10.1038/nature01964

Ekstrom, A. D., and Watrous, A. J. (2014). Multifaceted roles for low-frequency oscillations in bottom-up and top-down processing during navigation and memory. Neuroimage 85, 667-677. doi: 10.1016/j.neuroimage.2013.06.049

Ekstrom, A., Suthana, N., Millett, D., Fried, I., and Bookheimer, S. (2009). Correlation between BOLD fMRI and theta-band local field potentials in the human hippocampal area. J. Neurophysiol. 101, 2668-2678. doi: 10.1152/jn.91252. 2008

Engel, A. K., Fries, P., and Singer, W. (2001). Dynamic predictions: oscillations and synchrony in top-down processing. Nat. Rev. Neurosci. 2, 704-716. doi: $10.1038 / 35094565$

Fell, J., and Axmacher, N. (2011). The role of phase synchronization in memory processes. Nat. Rev. Neurosci. 12, 105-118. doi: 10.1038/nrn2979

Fell, J., Fernández, G., Klaver, P., Axmacher, N., Mormann, F., Haupt, S., et al. (2006). Rhinal-hippocampal coupling during declarative memory formation: dependence on item characteristics. Neurosci. Lett. 407, 37-41. doi: 10.1016/j.neulet.2006.07.074

Fell, J., Klaver, P., Elfadil, H., Schaller, C., Elger, C. E., and Fernández, G. (2003). Rhinal-hippocampal theta coherence during declarative memory formation: interaction with gamma synchronization? Eur. J. Neurosci. 17, 1082-1088. doi: 10.1046/j.1460-9568.2003.02522.x

Fell, J., Klaver, P., Lehnertz, K., Grunwald, T., Schaller, C., Elger, C. E., et al. (2001). Human memory formation is accompanied by rhinal-hippocampal coupling and decoupling. Nat. Neurosci. 4, 1259-1264. doi: 10.1038/nn759

Fell, J., Ludowig, E., Rosburg, T., Axmacher, N., and Elger, C. E. (2008). Phase-locking within human mediotemporal lobe predicts memory formation. Neuroimage 43, 410-419. doi: 10.1016/j.neuroimage.2008.07.021

Felleman, D. J., and Van Essen, D. C. (1991). Distributed hierarchical processing in the primate cerebral cortex. Cereb. Cortex 1, 1-47. doi: 10.1093/cercor/1.1.1

Foster, B. L., Kaveh, A., Dastjerdi, M., Miller, K. J., and Parvizi, J. (2013). Human retrosplenial cortex displays transient theta phase locking with medial temporal cortex prior to activation during autobiographical memory retrieval. J. Neurosci. 33, 10439-10446. doi: 10.1523/JNEUROSCI.0513-13.2013

Freeman, W. J., and Schneider, W. (1982). Changes in spatial patterns of rabbit olfactory EEG with conditioning to odors. Psychophysiology 19, 44-56. doi: 10.1111/j.1469-8986.1982.tb02598.x

Fries, P. (2005). A mechanism for cognitive dynamics: neuronal communication through neuronal coherence. Trends Cogn. Sci. 9, 474-480. doi: 10.1016/j.tics.2005.08.011

Friese, U., Köster, M., Hassler, U., Martens, U., Trujillo-Barreto, N., and Gruber, T. (2013). Successful memory encoding is associated with increased cross-frequency coupling between frontal theta and posterior gamma oscillations in human scalp-recorded EEG. Neuroimage 66, 642-647. doi: 10.1016/j.neuroimage.2012. 11.002

Fuentemilla, L., Penny, W. D., Cashdollar, N., Bunzeck, N., and Düzel, E. (2010). Theta-coupled periodic replay in working memory. Curr. Biol. 20, 606-612. doi: 10.1016/j.cub.2010.01.057

Gelbard-Sagiv, H., Mukamel, R., Harel, M., Malach, R., and Fried, I. (2008). Internally generated reactivation of single neurons in human hippocampus during free recall. Science 322, 96-101. doi: 10.1126/science.1164685

Giocomo, L. M., and Hasselmo, M. E. (2008). Time constants of h current in layer ii stellate cells differ along the dorsal to ventral axis of medial entorhinal cortex. J. Neurosci. 28, 9414-9425. doi: 10.1523/JNEUROSCI.3196-08.2008

Giocomo, L. M., Zilli, E. A., Fransén, E., and Hasselmo, M. E. (2007). Temporal frequency of subthreshold oscillations scales with entorhinal grid cell field spacing. Science 315, 1719-1722. doi: 10.1126/science.1139207

Givens, B. (1996). Stimulus-evoked resetting of the dentate theta rhythm: relation to working memory. Neuroreport 8, 159-163. doi: 10.1097/00001756-19961220000032

Godden, D. R., and Baddeley, A. D. (1975). Context-dependent memory in two natural environments: on land and underwater. Br. J. Psychol. 66, 325-331. doi: 10.1111/j.2044-8295.1975.tb01468.x

Gordon, A. M., Rissman, J., Kiani, R., and Wagner, A. D. (2013). Cortical reinstatement mediates the relationship between content-specific encoding activity and subsequent recollection decisions. Cereb. Cortex doi: 10.1093/cercor/bht194 [Epub ahead of print].

Goutagny, R., Jackson, J., and Williams, S. (2009). Self-generated theta oscillations in the hippocampus. Nat. Neurosci. 12, 1491-1493. doi: 10.1038/nn.2440

Groppe, D. M., Bickel, S., Keller, C. J., Jain, S. K., Hwang, S. T., Harden, C., etal. (2013). Dominant frequencies of resting human brain activity as measured by the electrocorticogram. Neuroimage 79, 223-233. doi: 10.1016/j.neuroimage.2013.04.044

Gu, N., Jackson, J., Goutagny, R., Lowe, G., Manseau, F., and Williams, S. (2013). NMDA-dependent phase synchronization between septal and temporal CA3 hippocampal networks. J. Neurosci. 33, 8276-8287. doi: 10.1523/JNEUROSCI.017913.2013

Gutfreund, Y., Yarom, Y., and Segev, I. (1995). Subthreshold oscillations and resonant frequency in guinea-pig cortical neurons: physiology and modelling. J. Physiol. 483(Pt 3), 621-640.

Harris, K. D., Csicsvari, J., Hirase, H., Dragoi, G., and Buzsáki, G. (2003). Organization of cell assemblies in the hippocampus. Nature 424, 552-556. doi: 10.1038/nature01834

Hasselmo, M. E., Bodelón, C., and Wyble, B. P. (2002). A proposed function for hippocampal theta rhythm: separate phases of encoding and retrieval enhance reversal of prior learning. Neural Comput. 14, 793-817. doi: $10.1162 / 089976602317318965$

Hebb, D. O. (1949). The Organization of Behavior. New York: Wiley \& Sons. 
Henrie, J. A., and Shapley, R. (2005). LFP power spectra in V1 cortex: the graded effect of stimulus contrast. J. Neurophysiol. 94, 479-490. doi: 10.1152/jn.00919.2004

Hoffman, K. L., and McNaughton, B. L. (2002). Coordinated reactivation of distributed memory traces in primate neocortex. Science 297, 2070-2073. doi: 10.1126/science. 1073538

Houweling, A. R., Bazhenov, M., Timofeev, I., Grenier, F., Steriade, M., and Sejnowski, T. J. (2002). Frequency-selective augmenting responses by shortterm synaptic depression in cat neocortex. J. Physiol. 542, 599-617. doi: 10.1113/jphysiol.2001.012759

Hölscher, C., Anwyl, R., and Rowan, M. J. (1997). Stimulation on the positive phase of hippocampal theta rhythm induces long-term potentiation that can be depotentiated by stimulation on the negative phase in area CA1 in vivo. J. Neurosci. $17,6470-6477$

Hu, H., Vervaeke, K., and Storm, J. F. (2002). Two forms of electrical resonance at theta frequencies, generated by M-current, h-current and persistent $\mathrm{Na}+$ current in rat hippocampal pyramidal cells. J. Physiol. 545, 783-805. doi 10.1113/jphysiol.2002.029249

Huerta, P. T., and Lisman, J. E. (1993). Heightened synaptic plasticity of hippocampal CA1 neurons during a cholinergically induced rhythmic state. Nature 364, 723-725. doi: 10.1038/364723a0

Huerta, P. T., and Lisman, J. E. (1995). Bidirectional synaptic plasticity induced by a single burst during cholinergic theta oscillation in CA1 in vitro. Neuron 15 , 1053-1063. doi: 10.1016/0896-6273(95)90094-2

Hutcheon, B., and Yarom, Y. (2000). Resonance, oscillation and the intrinsic frequency preferences of neurons. Trends Neurosci. 23, 216-222. doi: 10.1016/S0166-2236(00)01547-2

Huxter, J., Burgess, N., and O'Keefe, J. (2003). Independent rate and temporal coding in hippocampal pyramidal cells. Nature 425, 828-832. doi: 10.1038/nature 02058

Izhikevich, E. M., Desai, N. S., Walcott, E. C., and Hoppensteadt, F. C. (2003). Bursts as a unit of neural information: selective communication via resonance. Trends Neurosci. 26, 161-167. doi: 10.1016/S0166-2236(03)00034-1

Jacobs, J., and Kahana, M. J. (2009). Neural representations of individual stimuli in humans revealed by gamma-band electrocorticographic activity. J. Neurosci. 29 10203-10214. doi: 10.1523/JNEUROSCI.2187-09.2009

Jacobs, J., Kahana, M. J., Ekstrom, A. D., and Fried, I. (2007). Brain oscillations control timing of single-neuron activity in humans. J. Neurosci. 27, 3839-3844. doi: 10.1523/JNEUROSCI.4636-06.2007

Jacobs, J., Lega, B., and Anderson, C. (2012). Explaining how brain stimulation can evoke memories. J. Cogn. Neurosci. 24, 553-563. doi: 10.1162/jocn_a_00170

Jacobs, J., Weidemann, C. T., Miller, J. F., Solway, A., Burke, J. F., Wei, X.-X., et al. (2013). Direct recordings of grid-like neuronal activity in human spatial navigation. Nat. Neurosci. 16, 1188-1190. doi: 10.1038/nn.3466

Jeewajee, A., Lever, C., Burton, S., O’Keefe, J., and Burgess, N. (2008). Environmental novelty is signaled by reduction of the hippocampal theta frequency. Hippocampus 18, 340-348. doi: 10.1002/hipo.20394

Jensen, O., and Lisman, J. E. (1998). An oscillatory short-term memory buffer model can account for data on the Sternberg task. J. Neurosci. 18, 10688-10699.

Jirsa, V., and Müller, V. (2013). Cross-frequency coupling in real and virtual brain networks. Front. Comput. Neurosci. 7:78. doi: 10.3389/fncom.2013.00078

Johnson, J. D., McDuff, S. G. R., Rugg, M. D., and Norman K. A. (2009). Recollection, familiarity, and cortical reinstatement: a multivoxel pattern analysis. Neuron 63 697-708. doi: 10.1016/j.neuron.2009.08.011

Jones, M. W., and Wilson, M. A. (2005). Theta rhythms coordinate hippocampalprefrontal interactions in a spatial memory task. PLoS Biol. 3:e402. doi: 10.1371/journal.pbio.0030402

Jutras, M. J., and Buffalo, E. A. (2010). Synchronous neural activity and memory formation. Curr. Opin. Neurobiol. 20, 150-155. doi: 10.1016/j.conb.2010. 02.006

Jutras, M. J., Fries, P., and Buffalo, E. A. (2009). Gamma-band synchronization in the Macaque hippocampus and memory formation. J. Neurosci. 29, 12521-12531. doi: 10.1523/JNEUROSCI.0640-09.2009

Jutras, M. J., Fries, P., and Buffalo, E. A. (2013). Oscillatory activity in the monkey hippocampus during visual exploration and memory formation. Proc. Natl. Acad. Sci. U.S.A. 110, 13144-13149. doi: 10.1073/pnas.1302351110

Kendrick, K. M., Zhan, Y., Fischer, H., Nicol, A. U., Zhang, X., and Feng, J. (2011). Learning alters theta amplitude, theta-gamma coupling and neuronal synchronization in inferotemporal cortex. BMC Neurosci. 12:55. doi: 10.1186/1471-2202-12-55

Khader, P. H., Jost, K., Ranganath, C., and Rösler, F. (2010). Theta and alpha oscillations during working-memory maintenance predict successful long-term memory encoding. Neurosci. Lett. 468, 339-343. doi: 10.1016/j.neulet.2009.11.028

Knight, R. (1996). Contribution of human hippocampal region to novelty detection. Nature 383, 256-259. doi: 10.1038/383256a0

Knight, R. T. (2007). Neuroscience. Neural networks debunk phrenology. Science 316, 1578-1579. doi: 10.1126/science.1144677

Knight, R. T., and Eichenbaum, H. (2013). Multiplexed memories: a view from human cortex. Nat. Neurosci. 16, 257-258. doi: 10.1038/nn.3341

Koch, G., Ponzo, V., Di Lorenzo, F., Caltagirone, C., and Veniero, D. (2013). Hebbian and anti-hebbian spike-timing-dependent plasticity of human cortico-cortical connections. J. Neurosci. 33, 9725-9733. doi: 10.1523/JNEUROSCI.4988-12.2013

Kramis, R., Vanderwolf, C. H., and Bland, B. H. (1975). Two types of hippocampal rhythmical slow activity in both the rabbit and the rat: relations to behavior and effects of atropine, diethyl ether, urethane, and pentobarbital. Exp. Neurol. 49, 58-85. doi: 10.1016/0014-4886(75)90195-8

Kraus, B. J., Ii, R. J. R., White, J. A., Eichenbaum, H., and Hasselmo, M. E. (2013). Hippocampal "time cells": time versus path integration. Neuron 78, 1090-1101. doi: 10.1016/j.neuron.2013.04.015

Lakatos, P., Karmos, G., Mehta, A. D., Ulbert, I., and Schroeder, C. E. (2008) Entrainment of neuronal oscillations as a mechanism of attentional selection. Science 320, 110-113. doi: 10.1126/science.1154735

Lavenex, P., and Amaral, D. (2000). Hippocampal-neocortical interaction: a hierarchy of associativity. Hippocampus 10, 420-430. doi: 10.1002/1098 1063(2000) 10:4<420::AID-HIPO8>3.0.CO;2-5

Lee, H., Simpson, G. V., Logothetis, N. K., and Rainer, G. (2005). Phase locking of single neuron activity to theta oscillations during working memory in monkey extrastriate visual cortex. Neuron 45, 147-156. doi: 10.1016/j.neuron.2004.12.025

Lega, B. C., Jacobs, J., and Kahana, M. (2011). Human hippocampal theta oscillations and the formation of episodic memories. Hippocampus 22, 748-761. doi: 10.1002/hipo.20937

Lenck-Santini, P.-P., Fenton, A. A., and Muller, R. U. (2008). Discharge properties of hippocampal neurons during performance of a jump avoidance task. J. Neurosci. 28, 6773-6786. doi: 10.1523/JNEUROSCI.5329-07.2008

Lever, C., Burton, S., Jeewajee, A., Wills, T. J., Cacucci, F., Burgess, N., et al. (2010). Environmental novelty elicits a later theta phase of firing in CA1 but not subiculum. Hippocampus 20, 229-234. doi: 10.1002/hipo.20671

Liebe, S., Hoerzer, G. M., Logothetis, N. K., and Rainer, G. (2012). Theta coupling between V4 and prefrontal cortex predicts visual short-term memory performance. Nat. Neurosci. 15, 456-462. doi: 10.1038/nn.3038

Lisman, J. (2005). The theta/gamma discrete phase code occuring during the hippocampal phase precession may be a more general brain coding scheme. Hippocampus 15, 913-922. doi: 10.1002/hipo.20121

Lisman, J. E., and Idiart, M. A. (1995). Storage of 7+/-2 short-term memories in oscillatory subcycles. Science $267,1512-1515$. doi: $10.1126 /$ science.7878473

Lisman, J. E., and Jensen, O. (2013). The theta-gamma neural code. Neuron 77, 1002-1016. doi: 10.1016/j.neuron.2013.03.007

Liu, H., Agam, Y., Madsen, J. R., and Kreiman, G. (2009). Timing, timing, timing: fast decoding of object information from intracranial field potentials in human visual cortex. Neuron 62, 281-290. doi: 10.1016/j.neuron.2009.02.025

Lopour, B. A., Tavassoli, A., Fried, I., and Ringach, D. L. (2013). Coding of Information in the phase of local field potentials within human medial temporal lobe. Neuron 79, 594-606. doi: 10.1016/j.neuron.2013.06.001

Macdonald, C. J., Lepage, K. Q., Eden, U. T., and Eichenbaum, H. (2011). Hippocampal "time cells" bridge the gap in memory for discontiguous events. Neuron 71, 737-749. doi: 10.1016/j.neuron.2011.07.012

Madison, D. V., Malenka, R. C., and Nicoll, R. A. (1991). Mechanisms underlying long-term potentiation of synaptic transmission. Annu. Rev. Neurosci. 14, 379397. doi: 10.1146/annurev.ne.14.030191.002115

Manning, J. R., Jacobs, J., Fried, I., and Kahana, M. J. (2009). Broadband shifts in local field potential power spectra are correlated with single-neuron spiking in humans. J. Neurosci. 29, 13613-13620. doi: 10.1523/JNEUROSCI.2041-09.2009

Manning, J. R., Polyn, S. M., Baltuch, G. H., Litt, B., and Kahana, M. J. (2011). Oscillatory patterns in temporal lobe reveal context reinstatement during memory search. Proc. Natl. Acad. Sci. U.S.A. 108, 12893-12897. doi: $10.1073 /$ pnas. 1015174108 
Manns, J. R., Zilli, E. A., Ong, K. C., Hasselmo, M. E., and Eichenbaum, H. (2007). Hippocampal CA1 spiking during encoding and retrieval: relation to theta phase. Neurobiol. Learn. Mem. 87, 9-20. doi: 10.1016/j.nlm.2006.05.007

Maris, E., Vugt, M. V., and Kahana, M. (2011). Spatially distributed patterns of oscillatory coupling between high-frequency amplitudes and low-frequency phases in human iEEG. Neuroimage 54, 836-850. doi: 10.1016/j.neuroimage.2010.09.029

Markram, H., Lübke, J., Frotscher, M., and Sakmann, B. (1997). Regulation of synaptic efficacy by coincidence of postsynaptic APs and EPSPs. Science 275, 213-215. doi: 10.1126/science.275.5297.213

Markram, H., Wang, Y., and Tsodyks, M. (1998). Differential signaling via the same axon of neocortical pyramidal neurons. Proc. Natl. Acad. Sci. U.S.A. 95, 5323-5328. doi: 10.1073/pnas.95.9.5323

Marr, D. (1971). Simple memory: a theory for archicortex. Philos. Trans. R. Soc. Lond. B Biol. Sci. 262, 23-81. doi: 10.1098/rstb.1971.0078

McCartney, H., Johnson, A. D., Weil, Z. M., and Givens, B. (2004). Theta reset produces optimal conditions for long-term potentiation. Hippocampus 14, 684687. doi: 10.1002/hipo.20019

McClelland, J. L., McNaughton, B. L., and O’Reilly, R. C. (1995). Why there are complementary learning systems in the hippocampus and neocortex. Psychol. Rev. 102, 419-457. doi: 10.1037/0033-295X.102.3.419

McFarland, W. L., Teitelbaum, H., and Hedges, E. K. (1975). Relationship between hippocampal theta activity and running speed in the rat. J. Comp. Physiol. Psychol. 88, 324-328. doi: 10.1037/h0076177

Miller, K. J. (2010). Broadband spectral change: evidence for a macroscale correlate of population firing rate? J. Neurosci. 30, 6477-6479. doi: 10.1523/JNEUROSCI.6401-09.2010

Mitchell, K. J., and Johnson, M. K. (2009). Source monitoring 15 years later: what have we learned from fMRI about the neural mechanisms of source memory? Psychol. Bull. 135, 638-677. doi: 10.1037/a0015849

Montgomery, S. M., Betancur, M. I., and Buzsáki, G. (2009). Behavior-dependent coordination of multiple theta dipoles in the hippocampus. J. Neurosci. 29, 13811394. doi: 10.1523/JNEUROSCI.4339-08.2009

Mormann, F., Dubois, J., Kornblith, S., Milosavljevic, M., Cerf, M., Ison, M., et al. (2011). A category-specific response to animals in the right human amygdala. Nat. Neurosci. 14, 1247-1249. doi: 10.1038/nn.2899

Mormann, F., Fell, J., Axmacher, N., Weber, B., Lehnertz, K., Elger, C. E., et al. (2005). Phase/amplitude reset and theta-gamma interaction in the human medial temporal lobe during a continuous word recognition memory task. Hippocampus 15, 890-900. doi: 10.1002/hipo.20117

Mormann, F., Kornblith, S., Quiroga, R. Q., Kraskov, A., Cerf, M., Fried, I., et al. (2008a). Latency and selectivity of single neurons indicate hierarchical processing in the human medial temporal lobe. J. Neurosci. 28, 8865-8872. doi: 10.1523/JNEUROSCI.1640-08.2008

Mormann, F., Osterhage, H., Andrzejak, R. G., Weber, B., Fernández, G., Fell, J., et al. (2008b). Independent delta/theta rhythms in the human hippocampus and entorhinal cortex. Front. Hum. Neurosci. 2:3. doi: 10.3389/neuro. 09.003

Morton, N. W., Kahana, M. J., Rosenberg, E. A., Baltuch, G. H., Litt, B., Sharan, A. D., et al. (2012). Category-specific neural oscillations predict recall organization during memory search. Cereb. Cortex 23, 2407-2422. doi: 10.1093/cercor/ bhs 229

Nadel, L., and Moscovitch, M. (1997). Memory consolidation, retrograde amnesia and the hippocampal complex. Curr. Opin. Neurobiol. 7, 217-227. doi 10.1016/S0959-4388(97)80010-4

Nadel, L., Samsonovich, A., Ryan, L., and Moscovitch, M. (2000). Multiple trace theory of human memory: computational, neuroimaging, and neuropsychological results. Hippocampus 10, 352-368. doi: 10.1002/1098-1063(2000)10:4<352::AIDHIPO2>3.0.CO;2-D

Narayanan, R., and Johnston, D. (2007). Long-term potentiation in rat hippocampal neurons is accompanied by spatially widespread changes in intrinsic oscillatory dynamics and excitability. Neuron 56, 1061-1075. doi: 10.1016/j.neuron.2007.10.033

Norman, K. A., and O'Reilly, R. C. (2003). Modeling hippocampal and neocortical contributions to recognition memory: a complementary-learning-systems approach. Psychol. Rev. 110, 611-646. doi: 10.1037/0033-295X.110.4.611

Ohl, F. W., Scheich, H., and Freeman, W. J. (2001). Change in pattern of ongoing cortical activity with auditory category learning. Nature 412, 733-736. doi: $10.1038 / 35089076$
O'Keefe, J., and Dostrovsky, J. (1971). The hippocampus as a spatial map. Preliminary evidence from unit activity in the freely-moving rat. Brain Res. 34, 171-175. doi: 10.1016/0006-8993(71)90358-1

Pastalkova, E., Itskov, V., Amarasingham, A., and Buzsáki, G. (2008). Internally generated cell assembly sequences in the rat hippocampus. Science 321, 13221327. doi: 10.1126/science. 1159775

Pavlides, C., Greenstein, Y. J., Grudman, M., and Winson, J. (1988). Long-term potentiation in the dentate gyrus is induced preferentially on the positive phase of theta-rhythm. Brain Res. 439, 383-387. doi: 10.1016/0006-8993(88)91499-0

Paz, R., Bauer, E. P., and Pare, D. (2008). Theta synchronizes the activity of medial prefrontal neurons during learning. Learn. Memory 15, 524-531. doi: 10.1101/lm.932408

Penley, S. C., Hinman, J. R., Long, L. L., Markus, E. J., Escabí, M. A., and Chrobak, J. J. (2013). Novel space alters theta and gamma synchrony across the longitudinal axis of the hippocampus. Front. Syst. Neurosci. 7:20. doi: 10.3389/fnsys.2013.00020

Peters, H. C., Hu, H., Pongs, O., Storm, J. F., and Isbrandt, D. (2005). Conditional transgenic suppression of $\mathrm{M}$ channels in mouse brain reveals functions in neuronal excitability, resonance and behavior. Nat. Neurosci. 8, 51-60. doi: $10.1038 / \mathrm{nn} 1375$

Pike, F. G., Goddard, R. S., Suckling, J. M., Ganter, P., Kasthuri, N., and Paulsen, O. (2000). Distinct frequency preferences of different types of rat hippocampal neurones in response to oscillatory input currents. J. Physiol. 529(Pt 1), 205-213. doi: 10.1111/j.1469-7793.2000.00205.x

Polanía, R., Nitsche, M. A., Korman, C., Batsikadze, G., and Paulus, W. (2012). The importance of timing in segregated theta phase-coupling for cognitive performance. Curr. Biol. 22, 1314-1318. doi: 10.1016/j.cub.2012.05.021

Quiroga, R. Q., Kraskov, A., Koch, C., and Fried, I. (2009). Explicit encoding of multimodal percepts by single neurons in the human brain. Curr. Biol. 19, 1308-1313. doi: 10.1016/j.cub.2009.06.060

Quiroga, R. Q., Reddy, L., Kreiman, G., Koch, C., and Fried, I. (2005). Invariant visual representation by single neurons in the human brain. Nature 435, 11021107. doi: $10.1038 /$ nature 03687

Raghavachari, S., Lisman, J. E., Tully, M., Madsen, J. R., Bromfield, E. B., and Kahana, M. J. (2006). Theta oscillations in human cortex during a workingmemory task: evidence for local generators. J. Neurophysiol. 95, 1630-1638. doi: 10.1152/jn.00409.2005

Ranganath, C., and Blumenfeld, R. S. (2005). Doubts about double dissociations between short- and long-term memory. Trends Cogn. Sci. 9, 374-380. doi: 10.1016/j.tics.2005.06.009

Ranganath, C., and D'Esposito, M. (2001). Medial temporal lobe activity associated with active maintenance of novel information. Neuron 31, 865-873. doi: 10.1016/S0896-6273(01)00411-1

Ranganath, C., Cohen, M. X., and Brozinsky, C. J. (2005). Working memory maintenance contributes to long-term memory formation: neural and behavioral evidence. J. Cogn. Neurosci. 17, 994-1010. doi: 10.1162/0898929054475118

Redondo, R. L., and Morris, R. G. M. (2011). Making memories last: the synaptic tagging and capture hypothesis. Nat. Rev. Neurosci. 12, 17-30. doi: $10.1038 / \mathrm{nrn} 2963$

Rizzuto, D. S., Madsen, J. R., Bromfield, E. B., Schulze-Bonhage, A., and Kahana, M. J. (2006). Human neocortical oscillations exhibit theta phase differences between encoding and retrieval. Neuroimage 31, 1352-1358. doi: 10.1016/j.neuroimage.2006.01.009

Rizzuto, D. S., Madsen, J. R., Bromfield, E. B., Schulze-Bonhage, A., Seelig, D., Aschenbrenner-Scheibe, R., et al. (2003). Reset of human neocortical oscillations during a working memory task. Proc. Natl. Acad. Sci. U.S.A. 100, 7931-7936. doi: 10.1073/pnas.0732061100

Roberts, M. J., Lowet, E., Brunet, N. M., Ter Wal, M., Tiesinga, P., Fries, P., et al. (2013). Robust gamma coherence between macaque V1 and V2 by dynamic frequency matching. Neuron 78, 523-536. doi: 10.1016/j.neuron.2013.03.003

Rutishauser, U., Mamelak, A. N., and Schuman, E. M. (2006). Single-trial learning of novel stimuli by individual neurons of the human hippocampus-amygdala complex. Neuron 49, 805-813. doi: 10.1016/j.neuron.2006.02.015

Rutishauser, U., Ross, I. B., Mamelak, A. N., and Schuman, E. M. (2010). Human memory strength is predicted by theta-frequency phase-locking of single neurons. Nature 464, 903-907. doi: 10.1038/nature08860

Salazar, R. F., Dotson, N. M., Bressler, S. L., and Gray, C. M. (2012). Contentspecific fronto-parietal synchronization during visual working memory. Science 338, 1097-1100. doi: 10.1126/science. 1224000 
Saleh, M., Reimer, J., Penn, R., Ojakangas, C. L., and Hatsopoulos, N. G. (2010). Fast and slow oscillations in human primary motor cortex predict oncoming behaviorally relevant cues. Neuron 65, 461-471. doi: 10.1016/j.neuron.2010. 02.001

Schroeder, C. E., Wilson, D. A., Radman, T., Scharfman, H., and Lakatos, P. (2010). Dynamics of Active Sensing and perceptual selection. Curr. Opin. Neurobiol. 20 172-176. doi: 10.1016/j.conb.2010.02.010

Schyns, P. G., Thut, G., and Gross, J. (2011). Cracking the code of oscillatory activity. PLoS Biol. 9:e1001064. doi: 10.1371/journal.pbio.1001064

Scoville, W. B., and Milner, B. (1957). Loss of recent memory after bilateral hippocampal lesions. J. Neurol. Neurosurg. Psychiatry. 20, 11-21. doi: 10.1136/jnnp.20.1.11

Sederberg, P. B., Kahana, M. J., Howard, M. W., Donner, E. J., and Madsen, J. R. (2003). Theta and gamma oscillations during encoding predict subsequent recall. J. Neurosci. 23, 10809-10814.

Shay, C. F., Boardman, I. S., James, N. M., and Hasselmo, M. E. (2012). Voltage dependence of subthreshold resonance frequency in layer II of medial entorhinal cortex. Hippocampus 22, 1733-1749. doi: 10.1002/hipo.22008

Shirvalkar, P. R., Rapp, P. R., and Shapiro, M. L. (2010). Bidirectional changes to hippocampal theta-gamma comodulation predict memory for recent spatial episodes. Proc. Natl. Acad. Sci. U.S.A. 107, 7054-7059. doi: 10.1073/pnas.0911184107

Siapas, A. G., Lubenov, E. V., and Wilson, M. A. (2005). Prefronta phase locking to hippocampal theta oscillations. Neuron 46, 141-151. doi: 10.1016/j.neuron.2005.02.028

Siegel, M., Donner, T. H., and Engel, A. K. (2012). Spectral fingerprints of largescale neuronal interactions. Nat. Rev. Neurosci. 13, 121-134. doi: 10.1038/ nrn3137

Siegel, M., Warden, M. R., and Miller, E. K. (2009). Phase-dependent neuronal coding of objects in short-term memory. Proc. Natl. Acad. Sci. U.S.A. 106, 21341 21346. doi: 10.1073/pnas.0908193106

Singh, N. C. N., and Theunissen, F. E. F. (2003). Modulation spectra of natural sounds and ethological theories of auditory processing. J. Acoust. Soc. Am. 114 3394-3411. doi: 10.1121/1.1624067

Sirota, A., Montgomery, S., Fujisawa, S., Isomura, Y., Zugaro, M., and Buzsáki, G. (2008). Entrainment of neocortical neurons and gamma oscillations by the hippocampal theta rhythm. Neuron 60, 683-697. doi: 10.1016/j.neuron.2008.09.014

Staresina, B. P., and Davachi, L. (2009). Mind the gap: binding experiences across space and time in the human hippocampus. Neuron 63, 267-276. doi: 10.1016/j.neuron.2009.06.024

Staudigl, T., and Hanslmayr, S. (2013). Theta oscillations at encoding mediate the context-dependent nature of human episodic memory. Curr. Biol. 23, 1101-1106. doi: 10.1016/j.cub.2013.04.074

Tayler, K. K., Tanaka, K. Z., Reijmers, L. G., and Wiltgen, B. J. (2012). Reactivation of neural ensembles during the retrieval of recent and remote memory. Curr. Biol. $23,1-8$.

Teyler, T. J., and Rudy, J. W. (2007). The hippocampal indexing theory and episodic memory: updating the index. Hippocampus 17, 1158-1169. doi 10.1002/hipo.20350

Tierney, P. L., Dégenètais, E., Thierry, A.-M., Glowinski, J., and Gioanni, Y. (2004). Influence of the hippocampus on inter neurons of the rat prefrontal cortex. Eur. J. Neurosci. 20, 514-524. doi: 10.1111/j.1460-9568.2004. 03501.x

Tohidi, V., and Nadim, F. (2009). Membrane resonance in bursting pacemaker neurons of an oscillatory network is correlated with network frequency. J. Neurosci. 29, 6427-6435. doi: 10.1523/JNEUROSCI.0545-09.2009

Tort, A. B. L., Komorowski, R. W., Manns, J. R., Kopell, N. J., and Eichenbaum, H. (2009). Theta-gamma coupling increases during the learning of item-context associations. Proc. Natl. Acad. Sci. U.S.A. 106, 20942-20477. doi: 10.1073/pnas.0911331106

Tsunada, J., Baker, A. E., Christison-Lagay, K. L., Davis, S. J., and Cohen, Y. E. (2011). Modulation of cross-frequency coupling by novel and repeated stimuli in the primate ventrolateral prefrontal cortex. Front. Psychol. 2:217. doi 10.3389/fpsyg.2011.00217

Tulving, E., and Thomson, D. M. (1973). Encoding specificity and retrieval processes in episodic memory. Psychol. Rev. 80, 352. doi: 10.1037/h0020071

Ulrich, D. (2002). Dendritic resonance in rat neocortical pyramidal cells. J. Neurophysiol. 87, 2753-2759. van der Meij, R., Kahana, M., and Maris, E. (2012). Phase-amplitude coupling in human electrocorticography is spatially distributed and phase diverse. J. Neurosci. 32, 111-123. doi: 10.1523/JNEUROSCI.4816-11.2012

van Gerven, M. A. J., Maris, E., Sperling, M., Sharan, A., Litt, B., Anderson, C., etal. (2013). Decoding the memorization of individual stimuli with direct human brain recordings. Neuroimage 70, 223-232. doi: 10.1016/j.neuroimage.2012.12.059

van Vugt, M. K., Schulze-Bonhage, A., Litt, B., Brandt, A., and Kahana, M. J. (2010). Hippocampal gamma oscillations increase with memory load. J. Neurosci. 30, 2694-2699. doi: 10.1523/JNEUROSCI.0567-09.2010

Vanderwolf, C. H. (1969). Hippocampal electrical activity and voluntary movement in the rat. Electroencephalogr. Clin. Neurophysiol. 26, 407-418. doi: 10.1016/00134694(69)90092-3

Vargha-Khadem, F., Gadian, D. G., Watkins, K. E., Connelly, A., Van Paesschen, W., and Mishkin, M. (1997). Differential effects of early hippocampal pathology on episodic and semantic memory. Science 277, 376-380. doi: 10.1126/science. 277.5324 .376

Voytek, B., Canolty, R. T., Shestyuk, A., Crone, N. E., Parvizi, J., and Knight, R. T. (2010). Shifts in gamma phase-amplitude coupling frequency from theta to alpha over posterior cortex during visual tasks. Front. Hum. Neurosci. 4:191. doi: 10.3389/fnhum.2010.00191

Wang, W.-T., Wan, Y.-H., Zhu, J.-L., Lei, G.-S., Wang, Y.-Y., Zhang, P., et al. (2006). Theta-frequency membrane resonance and its ionic mechanisms in rat subicular pyramidal neurons. Neuroscience 140, 45-55. doi: 10.1016/j.neuroscience.2006.01.033

Watrous, A. J., Fried, I., and Ekstrom, A. D. (2011). Behavioral correlates of human hippocampal delta and theta oscillations during navigation. J. Neurophysiol. 105, 1747-1755. doi: 10.1152/jn.00921.2010

Watrous, A. J., Tandon, N., Conner, C. R., Pieters, T., and Ekstrom, A. D. (2013a). Frequency-specific network connectivity increases underlie accurate spatiotemporal memory retrieval. Nat. Neurosci. 16, 349-356. doi: 10.1038/ nn. 3315

Watrous, A. J., Lee, D. J., Izadi, A., Gurkoff, G. G., Shahlaie, K., and Ekstrom, A. D. (2013b). A comparative study of human and rat hippocampal lowfrequency oscillations during spatial navigation. Hippocampus 23, 656-661. doi: 10.1002/hipo.22124

Weiss, S., Müller, H. M., and Rappelsberger, P. (2000). Theta synchronization predicts efficient memory encoding of concrete and abstract nouns. Neuroreport 11 , 2357-2361. doi: 10.1097/00001756-200008030-00005

Weiss, S., and Rappelsberger, P. (2000). Long-range EEG synchronization during word encoding correlates with successful memory performance. Brain Res. Cogn. Brain Res. 9, 299-312. doi: 10.1016/S0926-6410(00)00011-2

Whishaw, I. Q., and Vanderwolf, C. H. (1973). Hippocampal EEG and behavior: changes in amplitude and frequency of RSA (theta rhythm) associated with spontaneous and learned movement patterns in rats and cats. Behav. Biol. 8, 461-484. doi: 10.1016/S0091-6773(73)80041-0

Whittingstall, K., and Logothetis, N. K. (2009). Frequency-band coupling in surface EEG reflects spiking activity in monkey visual cortex. Neuron 64, 281-289. doi: 10.1016/j.neuron.2009.08.016

Wilson, D. I. G., Langston, R. F., Schlesiger, M. I., Wagner, M., Watanabe, S., and Ainge, J. A. (2013). Lateral entorhinal cortex is critical for novel object-context recognition. Hippocampus 23, 352-366. doi: 10.1002/hipo. 22095

Wimber, M., Maaß, A., Staudigl, T., Richardson-Klavehn, A., and Hanslmayr, S. (2012). Rapid memory reactivation revealed by oscillatory entrainment. Curr. Biol. 22, 1482-1486. doi: 10.1016/j.cub.2012.05.054

Womelsdorf, T., Schoffelen, J.-M., Oostenveld, R., Singer, W., Desimone, R., Engel, A. K., etal. (2007). Modulation of neuronal interactions through neuronal synchronization. Science 316, 1609-1612. doi: 10.1126/science. 1139597

Yonelinas, A. P., Kroll, N. E. A., Quamme, J. R., Lazzara, M. M., Sauvé, M.-J., Widaman, K. F., et al. (2002). Effects of extensive temporal lobe damage or mild hypoxia on recollection and familiarity. Nat. Neurosci. 5, 1236-1241. doi: $10.1038 / \mathrm{nn} 961$

Conflict of Interest Statement: The authors declare that the research was conducted in the absence of any commercial or financial relationships that could be construed as a potential conflict of interest. 
Received: 18 September 2013; accepted: 29 January 2014; published online: 18 February 2014.

Citation: Watrous AJ and Ekstrom AD (2014) The spectro-contextual encoding and retrieval theory of episodic memory. Front. Hum. Neurosci. 8:75. doi: 10.3389/fnhum. 2014.00075

This article was submitted to the journal Frontiers in Human Neuroscience.
Copyright (C) 2014 Watrous and Ekstrom. This is an open-access article distributed under the terms of the Creative Commons Attribution License (CC BY). The use, distribution or reproduction in other forums is permitted, provided the original author(s) or licensor are credited and that the original publication in this journal is cited, in accordance with accepted academic practice. No use, distribution or reproduction is permitted which does not comply with these terms. 